\title{
The Effect of Bandwidth on Telerobot System Performance
}

Mark Uebel,

$7=$

Michael S. Ali,

and Ioannis Minis
$N 91-3 n 340$

Uncl is

H1/37 0038025 

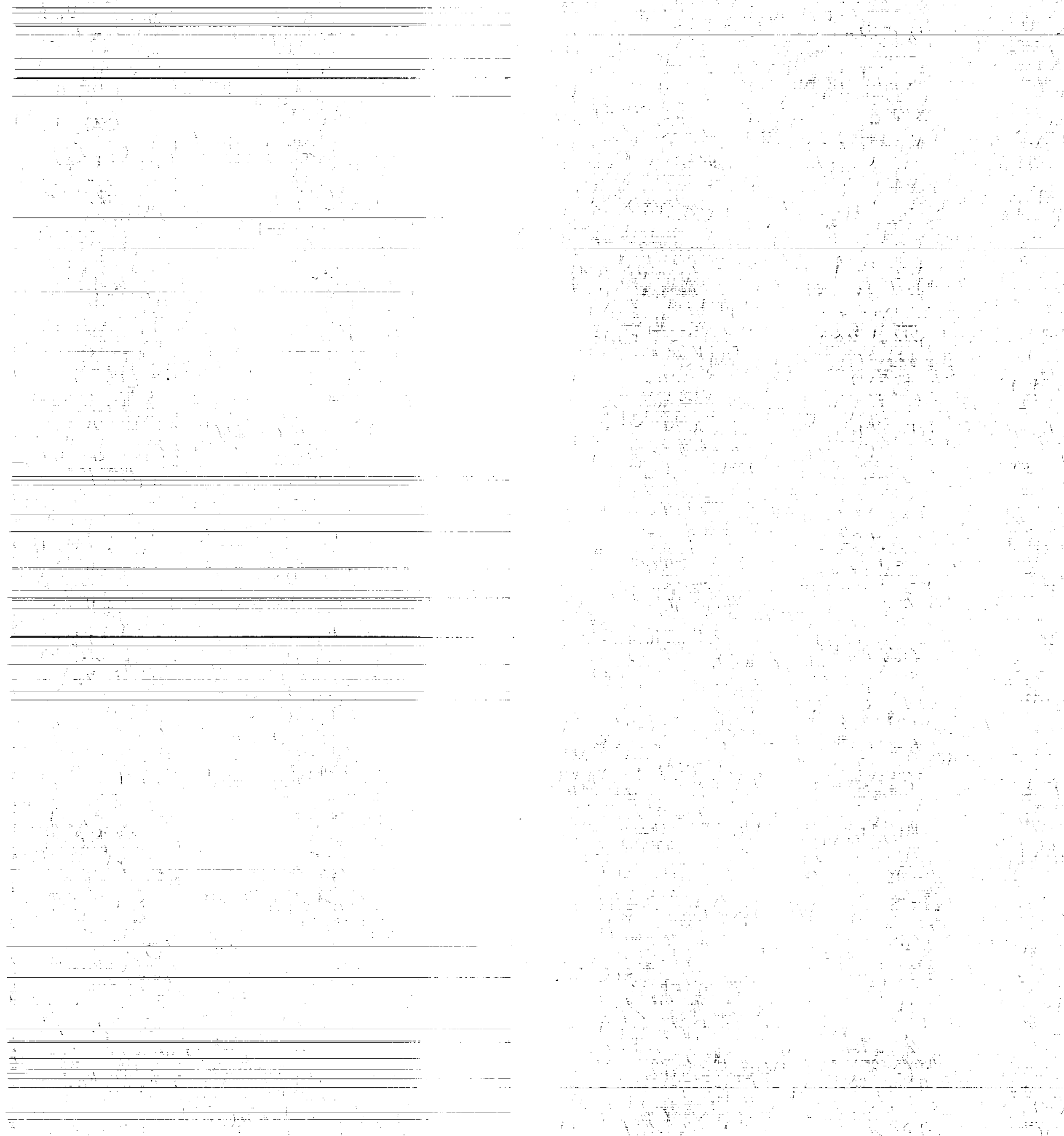
NASA

Technical

Paper

3152

1991

The Effect of Bandwidth

on Telerobot System

Performance

Mark Uebel

University of Maryland

College Park, Maryland

Michael S. Ali

Goddard Space Flight Center

Greenbelt, Maryland

Ioannis Minis

University of Maryland

College Park, Maryland

National Aeronautics and

Space Administration

Office of Management

Scientific and Technical Information Program 


\section{Preface}

The purpose of this experiment was to determine the effect that various slave-joint bandwidths have on telerobot system performance. The telerobot system consisted of a Robotics Research Corporation slave arm controlled by a Kraft Telerobotics master. The slave incorporated an impedance loop to provide local compliance in addition to the compliance provided by the operator via force feedback. Three joint bandwidths, 0.5 , 1.0 , and $2.0 \mathrm{~Hz}$ were used in the study. The performance measures were the task completion time and the sums of the squared forces and moments exerted on the environment. The task consisted of peg-in-hole insertion and removal. The results of the experiment indicate a significant performance decrease at $0.5 \mathrm{~Hz}$ bandwidth relative to the $1-$ and $2-\mathrm{Hz}$ bandwidths. There was no significant change in performance between the 1 and $2 \mathrm{~Hz}$ bandwidths. 


\section{CONTENTS}

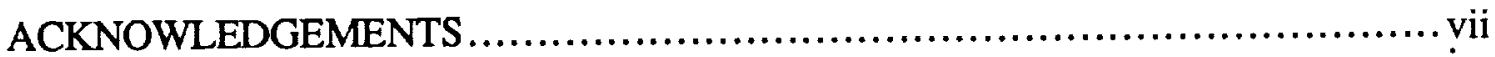

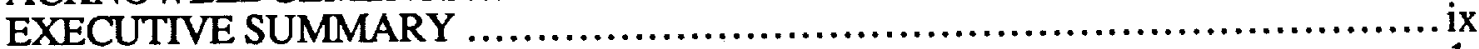

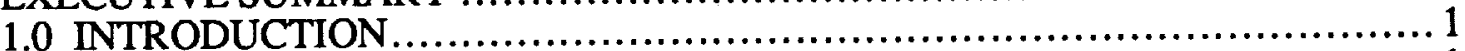

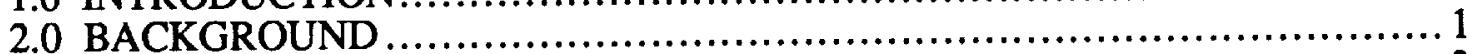

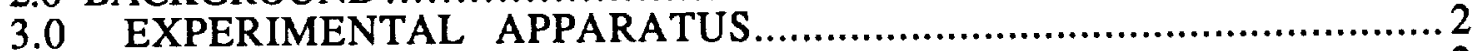

3.1 Telerobot System ........................................................ 2

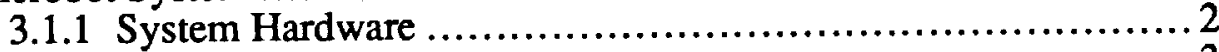

3.1.2 System Software .......................................... 3

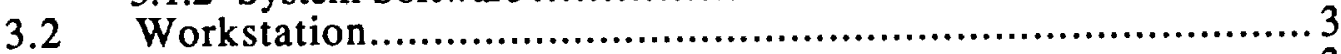

3.2.1 Operator Workstation ...................................... 3

3.2.2 Task Panel............................................................. 3

3.3 Data Acquisition and Analysis System .................................. 6

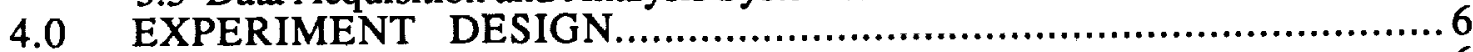

4.1 Factor Selection ......................................................... 6

4.2 Selection of Performance Measures .....................................6

4.3 Setting of Parameters................................................... 7

4.4 Experimental Procedures.......................................................

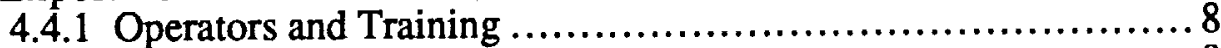

4.4.2 Peg-in-hole Task Procedure .......................................... 8

4.5 Analysis Procedures................................................... 8

5.0 RESULTS AND DISCUSSION ................................................... 10

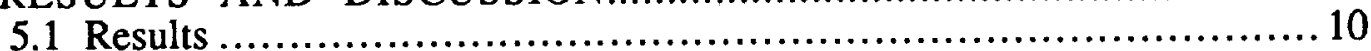

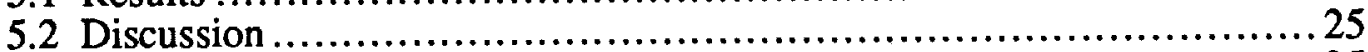

6.0 CONCLUSIONS AND FURTHER RESEARCH ............................. 25

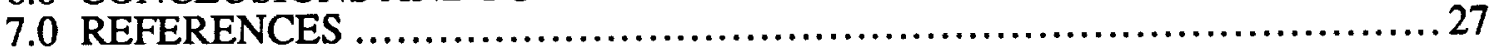

Appendix A

Telerobot System Parameters .............................................. 28

Appendix B

Explanation of SOSF and SOSM Results .................................... 29

Appendix C

Post Hoc Analysis...................................................................... 30

Appendix D

Experiment Script for Bandwidth Testing 
Glossary of abbreviations and acronyms

$\begin{array}{ll}\text { ANOVA } & \text { ANalysis Of VAriance } \\ \text { CT } & \text { Completion Time } \\ \text { DOF } & \text { Degrees Of Freedom } \\ \text { DTF-1 } & \text { Development Test Flight-1 } \\ \text { ETB } & \text { Engineering Testbed } \\ \text { FTS } & \text { Flight Telerobotic Servicer } \\ \text { m } & \text { meters } \\ \text { MacADIOS } & \text { MacIntosh Analog/Digital I/O System } \\ \text { N } & \text { Newtons } \\ \text { RRC } & \text { Robotics Research Corporation } \\ \text { S, sec } & \text { Seconds } \\ \text { SOSF } & \text { Sum of Squared Forces } \\ \text { SOSM } & \text { Sum of Squared Moments }\end{array}$




\section{ACKNOWLEDGEMENTS}

The authors wish to thank the following people for their substantial technical contributions to this study: Dr. Blake Hannaford, Dr. Won S. Kim, Dr. Wayne Book, Dr. Steve Wiker, Dr. Craig Carignan, and Dr. John Molino. Special thanks also to our test subjects: Robert Gorman, George Voellmer, Gary Mosier, Paul Richards, Maris Juberts, and Peter Yasuda. Finally, we would like to acknowledge the people who put the telerobot system together: Stephen Leake, Dana Miller, John Bjorge, and Kong Ha.

This work was funded by the Robotics Section of the Goddard Electromechanical Branch (Code 716.4) and by the Flight Telerobotic Servicer Project Office. 



\section{EXECUTIVE SUMMARY}

A central issue in telerobot system design is to relate system performance to the values of key system parameters such as bandwidth, cycle rate, latency, scale factors, and impedance. One of the purposes of the Engineering Testbed (ETB) at Goddard Space Flight Center (GSFC) is to quantify these relationships. To address these issues methodically, a group of experts from GSFC, Martin Marietta, and the University of Maryland developed a list of parameters that significantly affect system performance. Among these parameters, the slave-joint bandwidth was the most important factor.

An extensive literature search uncovered several papers related to the issue of teleoperator system performance. In addition, researchers in this area (from JPL, University of Wisconsin, Georgia Tech, and GSFC) were interviewed by phone and in person. This research resulted in an experiment designed to give statistically valid results on the effect of joint bandwidth on three measures of task performance: completion time (CT), the sum of squared forces (SOSF), and the sum of squared moments (SOSM). Six well-trained operators performed five repetitions of a peg-in-hole task for each of three bandwidths. The bandwidths chosen were those currently being considered for the demonstration test flight (DTF-1) of the Flight Telerobotic Servicer (FTS): 0.5, 1.0, and $2.0 \mathrm{~Hz}$.

The telerobot system consisted of a Robotics Research Corporation (RRC) slave arm and a Kraft Telerobotics master arm. User-selected gains set the RRC joint bandwidths to the experimental values. An impedance filter in the slave control loop reduced the slave arm Cartesian stiffness to that of the DTF-1 manipulator ( $5 \mathrm{lbs} / \mathrm{in}$ ). The cycle rate of the control loop was $50 \mathrm{~Hz}$ (also planned for DTF-1). The system around-the-loop time was $20 \mathrm{~ms}$. Excluding stiffness, all values were confirmed experimentally.

Tuning the system consisted of setting the force reflection and position scale factors and the impedance filter damping. Position and force feedback scaling were set at 4:1 for position and 30:1 for force feedback. While these position and force reflection gains are low relative to other state-of-the-art systems, the results of this experiment should apply at least qualitatively to other, more highperformance, systems. The impedance filter damping was set to the lowest value consistent with stable performance of the peg-in-hole task. Note that in the present study, no attempt was made to optimize these parameters.

An Apple Macintosh-based data acquisition system collected the data from the force/torque sensor. The CT, SOSF, and SOSM were all computed from the resulting force record. Analysis of variance (ANOVA) techniques assesed the significance of the effects of bandwidth on the performance metrics.

The experimental results indicate poor system performance at the $0.5-\mathrm{Hz}$ bandwidth relative to the performance at 1.0 and $2.0 \mathrm{~Hz}$. The results also indicate no statistically significant difference in performance between the $1.0-$ and $2.0-\mathrm{Hz}$ bandwidths.

One possible explanation of the CT results is that the frequency content of the operator's motion commands is between 0.5 and $2.0 \mathrm{~Hz}$. The SOSF and SOSM results may be attributed to the effect of the impedance loop when the robot is in contact with the environment. A model of the system at 0.5 $\mathrm{Hz}$ has significantly less phase margin than at the 1 or $2 \mathrm{~Hz}$ bandwidth settings. The low phase margin at $0.5 \mathrm{~Hz}$ leads to underdamped oscillatory behavior in contact. This behavior leads to large forces and moments exerted on the environment. This behavior could also have a negative impact on the CT. In contrast, the 1- and 2- $\mathrm{Hz}$ systems have better damping than the $0.5 \mathrm{~Hz}$ system. Validation of these hypotheses should be the subject of future studies.

\section{PRECEDING PAGE BLANK NOT FILMED}


新和- 


\subsection{INTRODUCTION}

The Engineering Test Bed (ETB) at Goddard Space Flight Center (GSFC) support NASA Goddard's efforts in space robotics. Recently, the ETB initiated a study to examine the effects of slave joint position servo bandwidths on the performance of a telerobotic system. Given that a telerobot is a complex system driven by a human operator, it is not feasible to predict such effects analytically, and therefore, an experimental investigation was required. Understanding the role of joint bandwidth may enable the design of future space telerobotic systems for optimal performance. In particular, the results of these tests will aid in the design of NASA's first space robot, the Flight Telerobotic Servicer (FTS), and its prototype for Development Test Flight 1 (DTF-1).

This report details the experimental design and the results of the tests used to examine the effects of various free-space slave joint position bandwidths on telerobot performance. In Section 3 , the experimental apparatus is described, including the telerobot system, the workstation, and the data collection system. In Section 4, the design of experiments is discussed, including selection of factors, performance metrics, experimental design, the setting and verification of the telerobot parameters, the experimental procedures and a description of the analysis procedures. In Section 5, the results and discussion of the results are presented. Section 6 contains the conclusions and suggestions for further research.

\subsection{BACKGROUND}

Bandwidth characterizes the frequency range up to the value corresponding to the -3 -dB magnitude on a Bode plot. For a nonlinear system (such as a robot), the frequency response can vary significantly with the state of the system and the shape of the input. For this reason, caution must be used when applying the term bandwidth to a nonlinear system. In this report, "joint bandwidth" will refer to the local (small movement), joint-position servo bandwidth (-3-dB magnitude) of each individual robot joint, uncoupled from the remaining joints. Experimental data demonstrate that for the Robotics Research Corporation (RRC) arm, the arm configuration has only a small effect on the measurable joint bandwidths. "Cartesian bandwidth" will refer to the Cartesian space bandwidth of the endeffector positioning servo. In this experiment, the task required Cartesian motions in less than a cubic foot of space. The manipulator therefore did not undergo major changes in its configuration.

There are varying views on the bandwidth requirements for a telerobotic system. An and Hollerbach [1987] describe three bandwidth test cases:

1) Manipulator in contact with stationary environment; force commands are issued.

2) Manipulator in contact with moving environment; constant force is commanded.

3) Manipulator in free space; position is commanded.

The first case concerns only the force control of the manipulator. The second configuration concerns both the force control and position control. The third configuration concerns only the position control of the manipulator. For this report, the joint bandwidth in the third case is applicable.

Brooks [1990a,1990b] surveyed several sources in the literature to establish a consensus on the bandwidth required for satisfactory performance of telerobotic systems. He reported that a human operator performs reflex motions with a maximum frequency content of up to $10 \mathrm{~Hz}$. Further, he reported that a human operator can generate trajectories with a maximum frequency content of up to 5 Hz. These facts would indicate that the telerobot system need not have a free-space Cartesian bandwidth greater than $10 \mathrm{~Hz}$, since the operator would never be capable of producing motions with greater frequency content. Given that $10 \mathrm{~Hz}$ is the maximum necessary bandwidth, the next question is what is the minimum acceptable bandwidth? 
In the same survey, several experts in the field of teleoperation were asked "What ... is the minimum acceptable master-slave frequency response for a tele-operated system?" Their answers ranged from $0.25 \mathrm{~Hz}$ to $10 \mathrm{~Hz}$. The general consensus was that less than $10 \mathrm{~Hz}$ is required (the median value was $5 \mathrm{~Hz}$ ). In addition to this survey, there are two experimental studies in the literature which address the bandwidth issue.

Book and Hannema [1980] performed experiments with a 2 degree-of-freedom (DOF), planar telerobot to determine the effects of various joint bandwidths on the system performance. They used completion time (CT) to quantify performance. Their control system provided the slave arm with a constant joint position bandwidth at all joint angles. The experimental results showed that there was improvement in task completion time as the slave manipulator joint bandwidth increased from 1 to 3.5 $\mathrm{Hz}$. However, little improvement was observed for bandwidths higher than $3.5 \mathrm{~Hz}$.

Kim, et al.[1987] performed simulation studies to assess the effects of several parameters, including joint bandwidth, on telemanipulator system performance. They simulated a 3-DOF robot performing a pick-and-place task. Completion time was the performance measure. The results showed an exponential increase in performance (exponentially decreasing CT) as the joint bandwidth increased. The curve began to approach its asymptotic value at a joint bandwidth of about $2 \mathrm{~Hz}$.

In comparison, this study is the first to employ an industrial manipulator. In addition, it is the first bandwidth study to use both completion time and exerted force/torque as performance measures.

\subsection{EXPERIMENTAL APPARATUS}

The apparatus used in the experiments has three major components which are described below: the telerobot system, the operator workstation, and the data collection system.

\subsection{Telerobot System}

\subsubsection{System Hardware}

The telerobot system hardware consists of an RRC arm and a Kraft Mini-Master Controller. Mounted on the last link of the arm is a JR3 force/torque sensor. The sensor contains anti-aliasing filters set at a cutoff frequency of $16 \mathrm{~Hz}$ since the sampling rate of the system was $50 \mathrm{~Hz}$. The peg for the peg-inhole task is mounted directly to the wrench sensor.

The control algorithms run on three Intel $386 / 31$ boards mounted in a Multibus I card rack. The RRC hardware is under the control of the Multibus I computers. Similarly, the Kraft Mini-Master Controller system communicates with the Multibus I. A simplified block diagram of the system is shown in Figure 3.1. While the RRC arm is a 7-DOF manipulator, the control algorithm only uses the last six joints. The base joint is essentially fixed. This eliminates the need for any redundancy resolution schemes. 


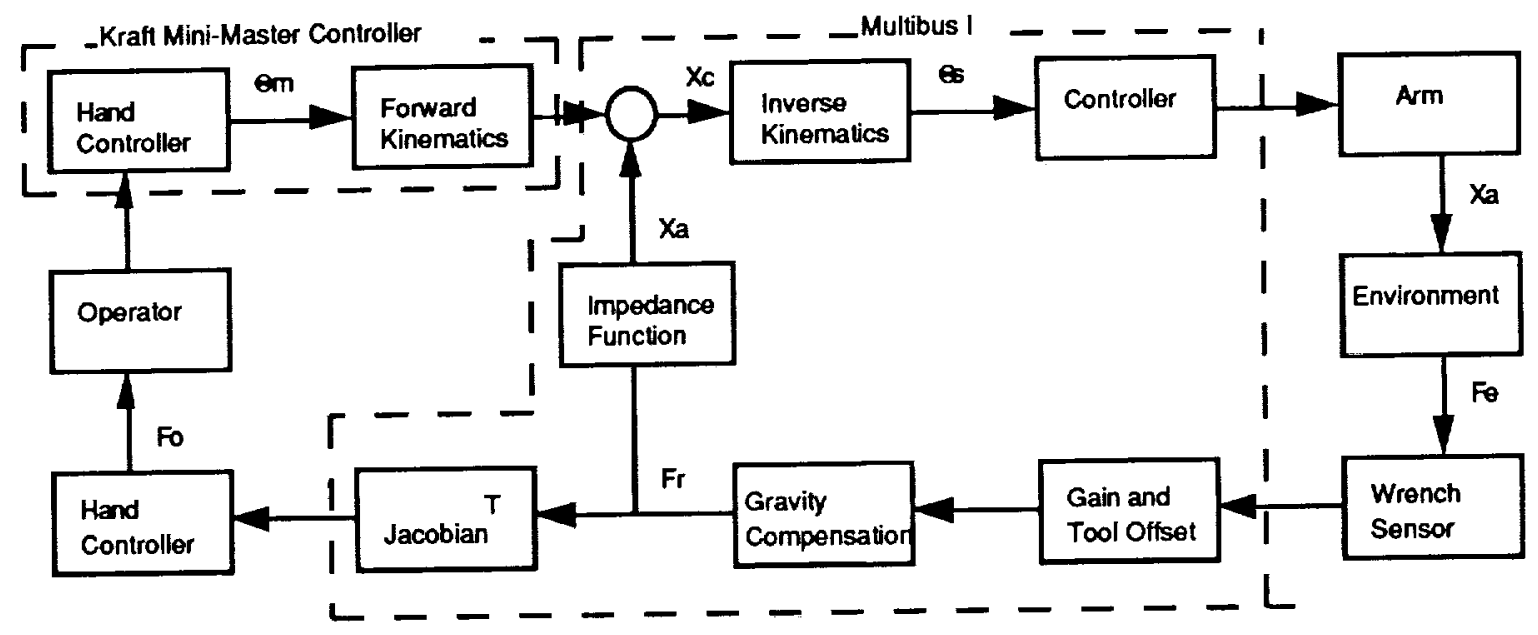

Figure 3.1. Block Diagram of Master/Slave System

\subsubsection{System Software}

The system software has several features which allow the telerobot system to operate in a variety of configurations. The options offered to the operator are: motion mapping, motion scaling, motion frame, indexing, axis selection, axis frame, force reflection, force reflection scaling, impedance stiffness, and impedance damping. See Appendix A for a description of some of these features. For a complete description see Leake [1990]. For this experiment, the values selected stayed the same for all trials.

\subsection{Workstation}

\subsubsection{Operator Workstation}

The operators performed all tasks from the workstation shown in Figure 3.2. A headset which played a "pink noise" background sound prevented auditory feedback from the task area. The operators were not allowed direct view of the task panel (described in the next section). Instead, the operators viewed the task panel via monitors connected to three cameras. The first camera was on the wrist of the robot arm viewing down the axis of the peg. The second camera was on the side of the task panel, viewing in a direction normal to the hole axis. The third camera was above and towards the side of the task panel.

\subsubsection{Task Panel}

The task panel, shown in Figure 3.3, is modular in design so that a variety of tasks can be implemented. For these tests, only a peg-in-hole task was used. The peg for the task was 16 inches long and 0.600 inch in diameter. The hole used for the task was 1 inch deep and 0.620 inch in diameter. 


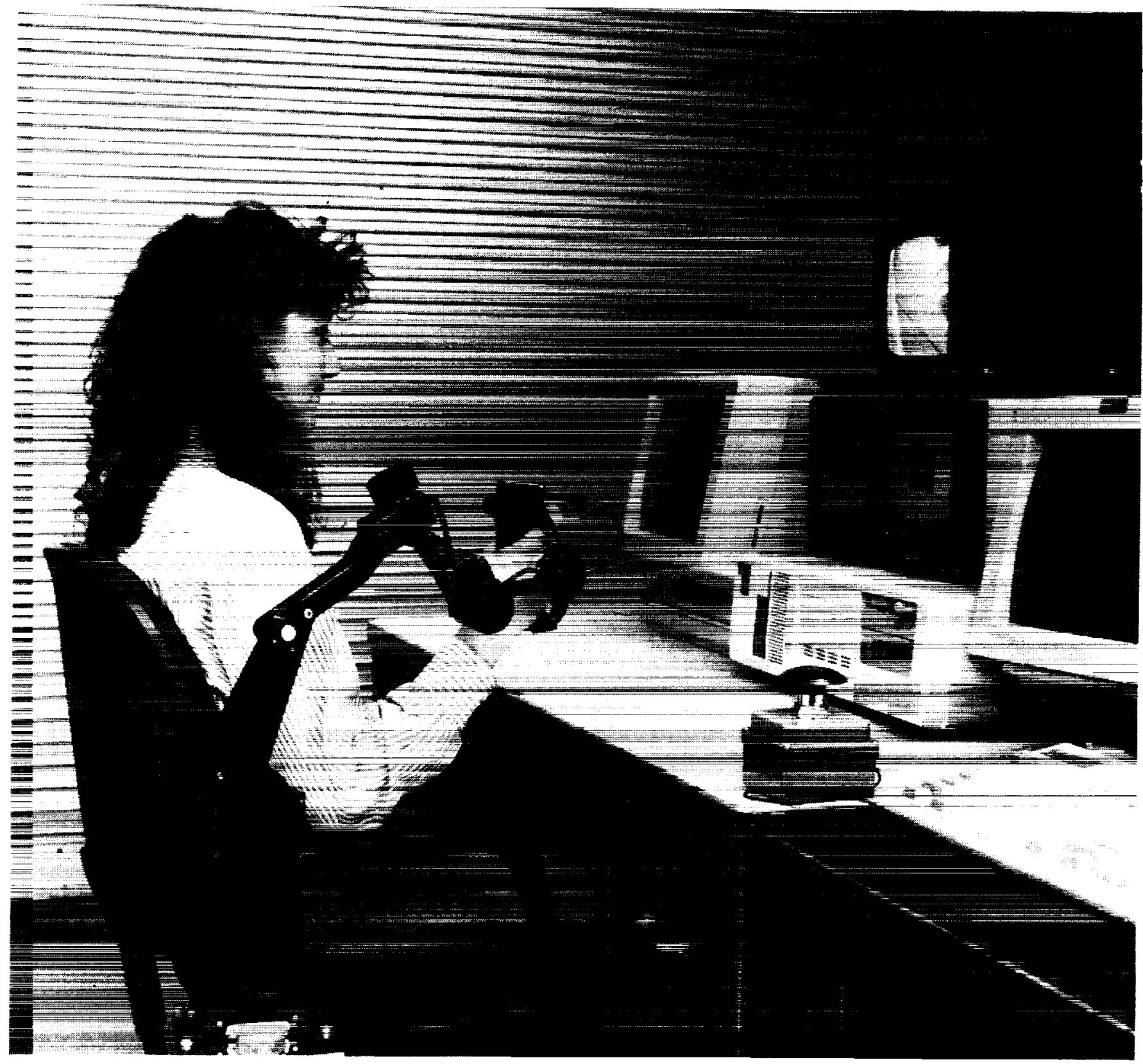

Figure 3.2. Operator Workstation

\author{
ORIGINAL PAGE \\ BLACK AND WHITE PHOTOGRAPH
}




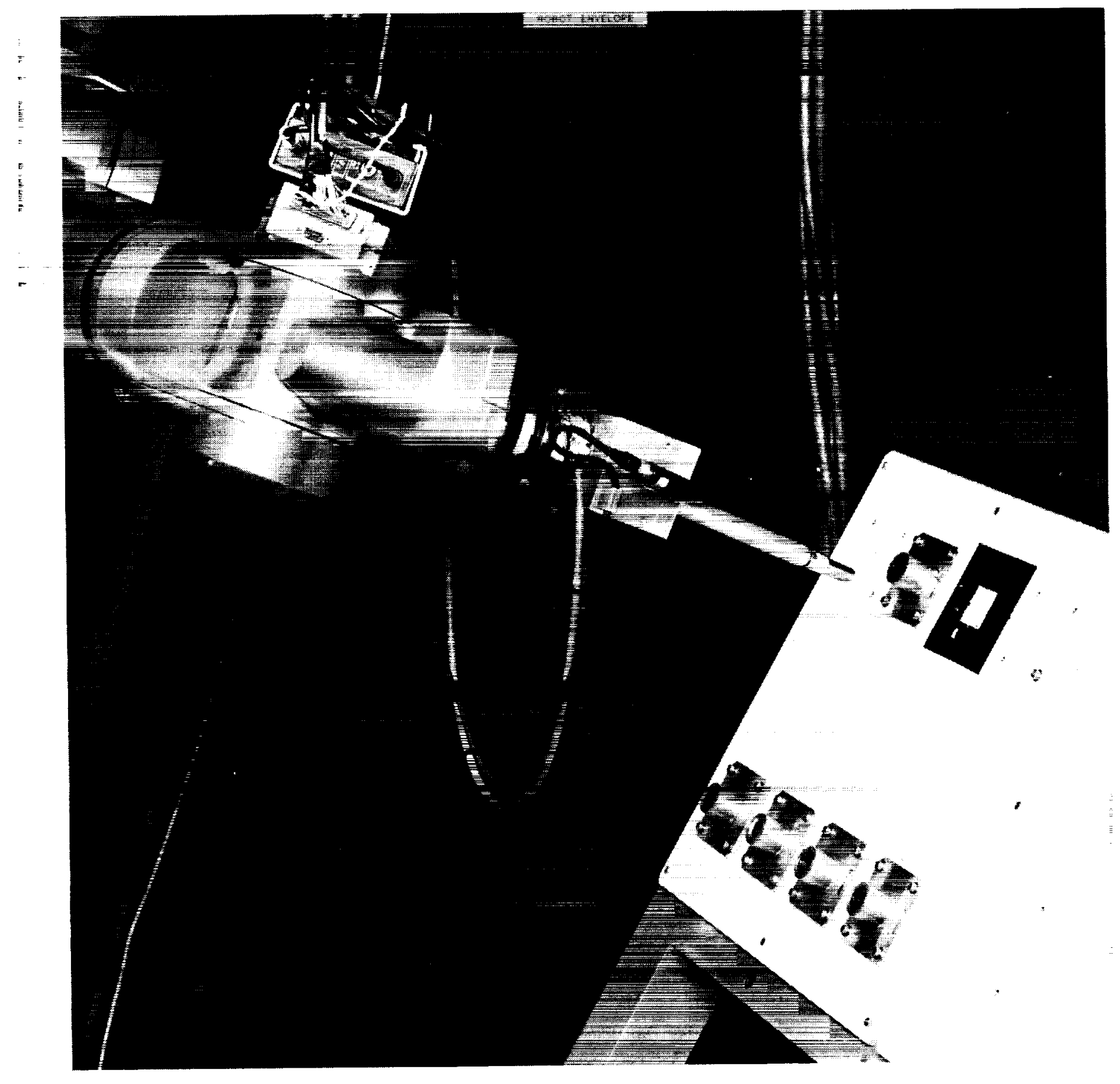

Figure 3.3. Task Panel

$$
\begin{gathered}
\text { ORIGINAL PAGE } \\
\text { BLACK AND WHITE PHOTOGRAPH }
\end{gathered}
$$




\subsection{Data Acquisition and Analysis System}

The data acquisition system recorded the data from the force/torque sensor. It consisted of a Macintosh II computer equipped with a MacADIOS (Analog/Digital I/O) board. Analog signals from the force/torque sensor were sampled at a rate of $50 \mathrm{~Hz}$ and stored in memory. Sampling of the raw data commenced once an initial tap was detected and continued for a fixed, user defined, time period. At the end of this period, the data were transferred from memory to a file on the hard disk.

Deriving the actual force components along the Cartesian coordinate axes required further processing of the raw force/torque data. The program developed for this purpose computed the metrics from the force records and stored them in a single file. Each record in the file contained the operator's name, the trial number, the repetition number, the completion time, the sum of squared forces, and the sum of squared moments.

\subsection{EXPERIMENT DESIGN}

\subsection{Factor Selection}

Several experts from GSFC, Martin Marietta, and the University of Maryland contributed to the list shown below. It lists all of the parameters (factors) of the telerobot system of interest, in order of importance. The suggested levels for each factor are also given.

1. Joint Position Bandwidth $(0.5,1,2 \mathrm{~Hz})$

2. Cycle rate $(50,100 \mathrm{~Hz})$

3. Force feedback (off, low, high)

4. Impedance function (off, low, high)

5. Pose (close to singularity and/or joint limit, etc.)

Other factors, external to the telerobot system, but which may influence performance:

6. Environmental Stiffness (low, high)

7. Task (peg-in-hole, contour board, truss node)

8. Number of operators $(6$ to 10$)$

Based on time constraints, the decision was made to determine the effect of the bandwidths (item \#1) on the system performance for the peg-in-hole task (item \#7), using an appropriate number of operators (item \#8). The remaining factors were maintained a nominal levels throughout the experiment. The peg-in-hole task combines both accuracy and dexterity requirements. A recent teleoperator study by Molino [1990] helped to determine the number of operators. For an alpha risk of $5 \%$ (95\% confidence level), calculations indicated that 6 operators performing 5 repetitions each yields statistically significant results for detecting a $15 \%$ reduction in task completion time (beta risk). Each operator performed several training runs to reduce or eliminate any learning effects.

This experiment uses a full factorial design; i.e., all operators performed the experiments at each bandwidth level for the specified number of repetitions. This provides the ability to determine any interaction effects between the operator and the joint bandwidth.

\subsection{Selection of Performance Measures}

The most common performance measure found in relevant studies is the completion time for the task (see Molino [1990], Hannaford and Wood [1989], and Draper, et al. [1987]). Recent tests have established that "force and torque data recorded from the robot wrist (is a) rich source of information 
on the performance of tasks" (Hannaford and Wood [1989]. Draper, et. al. [1987] concluded that

"tele-operator experiments should include measures of (1) the rate of task completion; (2) the accuracy or quality of task performance; (3) the impact of the system on the remote environment, especially damage or the potential for damage; and (4) the impact of the system on its human operator, especially fatigue and workload. Use of an incomplete set of variables may lead to incorrect conclusions concerning tele-operator performance."

Following these guidelines, the metrics chosen were the completion time (CT), the sum of squared forces (SOSF), and the sum of squared moments (SOSM). These metrics give an indication of the efficiency of task completion. Section 4.5, "Analysis Procedures" presents the expressions used to compute these measures from the data collected. Our definitions of SOSF and SOSM are equivalent to those used by Hannaford and Wood [1989].

\subsection{Setting of Parameters}

Several parameters of the telerobot system had to be tuned. The parameters included the position and force feedback scaling between the master and slave, the damping of the impedance filter, and the bandwidth of the joints. Damping, position scaling and force feedback scaling had to be specified such that the system remained stable. For this experiment, we tried to find the maximum (or minimum) value which allowed us to perform the peg-in-hole task in an "efficient" manner. Clearly, this is a subjective method. Future studies will address objective selection of these parameters.

The level of force feedback and position scaling were chosen by an experienced operator who performed the peg-in-hole task several times under various combinations of force and position scale values. The position scale was set such that the task could be completed by indexing only once. (See Appendix A for a definition of indexing.) The selected value of force reflection scaling allowed the operator to receive sufficient force information to aid in completing the task without becoming fatigued after several repetitions. Based on this subjective analysis, the value for the position scale was set to $4: 1$, and the force scale was set to $30: 1$.

The stiffness of the impedance filter was set to $5 \mathrm{lbs} /$ in to emulate the Cartesian stiffness of the DTF-1 arm. The damping constant was the minimum damping value compatible with stable execution of the peg-in-hole task. This turned out to be approximately $350 \mathrm{lb} / \mathrm{in} / \mathrm{sec}$.

A digital filter between the digital controller and the analog control hardware sets the desired joint bandwidth and damping. This approach is feasible since the analog hardware provides the robot with high $(5-8 \mathrm{~Hz})$ joint bandwidths compared to our desired maximum of $2 \mathrm{~Hz}$. The filter gives the joint a second-order response with a damping ratio of 0.707 .

The values of joint bandwidth, cycle rate, and system latency were validated during the experiment. Digital Fourier analysis of the motion resulting from square wave excitation of each joint determined the frequency response of the joint. Verification of the cycle rate $(50 \mathrm{~Hz})$ and the latency $(20 \mathrm{~ms})$ required software toggling of an $\mathrm{L} / \mathrm{O}$ port bit every cycle. The toggle frequency, as measured on an oscilloscope, determined the cycle rate and latency values.

\subsection{Experimental Procedures}

Each operator performed the peg-in-hole task for each of the three joint bandwidths, in a random order. This set of three tests comprised one repetition. Appendix D provides the step-by-step procedure used in the experiments. Each operator performed a total of five repetitions. Before the 
start of the actual tests, the operator performed two "warm-up" tasks.

\subsubsection{Operators and Training}

All six operators had technical background and some experience with teleoperated systems. Their ages ranged from 24 to 55 years old.

Each operator received 2 hours of training including a half-hour introduction to the telerobot system. During the introduction, the operators were exposed to the motion mapping of the master to the slave, the camera views, and the motions seen in each view. They received tips on system operation. Familiarization with the hand controller and its operation followed. Next, the operator used the hand controller to make free-space motions. Finally, the operator was allowed to contact the task panel. Tracing of a contour with the peg was used to familiarize the operator with the force feedback. Training also included several attempts of the peg-in-hole task.

\subsubsection{Peg-in-hole Task Procedure}

The task procedure consisted of first positioning the slave at the home position, 3 inches in front of the home square. A bandwidth, selected at random, was entered into the system. The operator then began the task after initiation of the data collection routine. The task consisted of four steps:

1. Tap panel at home square

2. Insert peg to bottom of hole

3. Remove peg from hole

4. Tap home square with peg

Note that the taps at the beginning and end of the task produce characteristic impulses in the force record. These impulses identify the start and end of the task.

\subsection{Analysis Procedures}

The measures CT, SOSF, and SOSM, were computed directly from the force data. A typical force record is shown in Figure 4.1. 


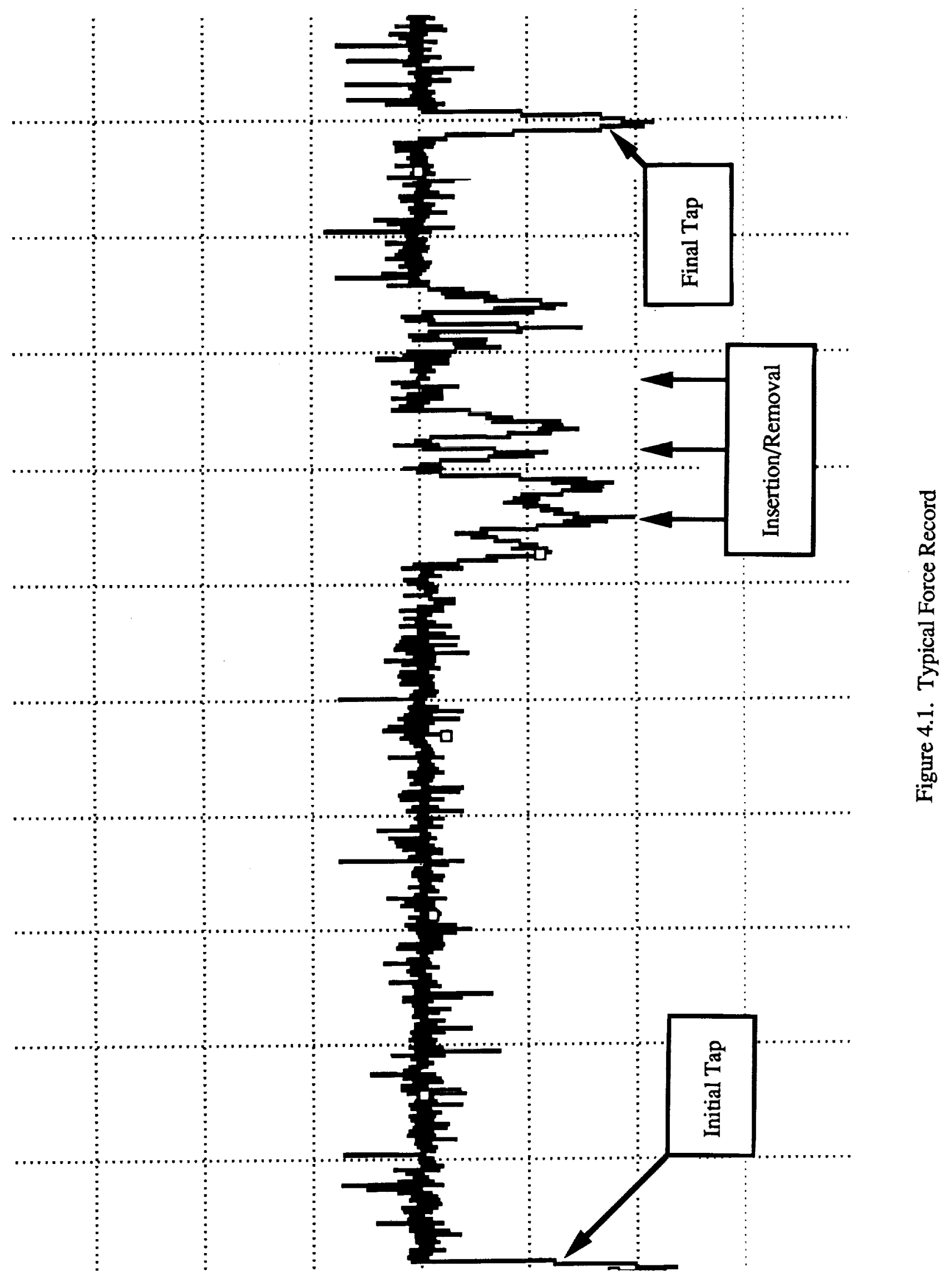


The analysis software computed completion time by identifying the end of each record. The SOSx (where $\mathrm{x}$ is " $\mathrm{F}$ " or " $\mathrm{M}$ ") was computed as:

$$
\operatorname{SOS} x=\sum_{i} \sum_{j} f_{i j}^{2} d t
$$

where: $f=$ force component

$\mathrm{ij}=\mathrm{i}^{\text {th }}$ sample of force along the $\mathrm{j}^{\text {th }}$ Cartesian axis

$\mathrm{i}=1$.. number of samples

$\mathrm{j}=1 . .3$ for SOSF, $4 . .6$ for SOSM

$\mathrm{dt}=$ sample rate

Note that this expression is equivalent to that used by Hannaford and Wood [1989]. The experimental data were analyzed using Analysis of Variance (ANOVA) techniques. The analysis considered the full factorial design with interaction between operator and bandwidth.

\subsection{RESULTS AND DISCUSSION}

\subsection{Results}

Figures $5.1 \mathrm{a}, \mathrm{b}$, and $\mathrm{c}$ show the data for completion time (CT), sum of squared forces (SOSF), and sum of squared moments (SOSM) as they were computed from the force/torque sensor records for each operator, bandwidth, and repetition. One data point was lost, the fifth repetition of the 2-Hz test for subject 2 . To complete the block for the statistical analysis, the value for the missing run was computed as the average of the other repetitions (a technique suggested in Ott [1984]).

Tables $5.1 \mathrm{a}, \mathrm{b}$, and c show the mean values and standard deviations of the measures CT, SOSF, and SOSM for each operator at each bandwidth. Figures $5.2 \mathrm{a}, \mathrm{b}$, and $\mathrm{c}$ show the CT, SOSF, and SOSM averaged across all operators and repetitions for each bandwidth. Tables $5.2 \mathrm{a}, \mathrm{b}$, and c list the data used in the figures. These figures indicate improved performance for the $1 \mathrm{~Hz}$ system in comparison to the $0.5-\mathrm{Hz}$ system. However, there is no observable change in performance from the $1 \mathrm{~Hz}$ to $2 \mathrm{~Hz}$ bandwidth values. To check the statistical significance of these observations, an analysis of variance was performed.

The results of the ANOVA for each of the dependent variables, completion time (CT), sum of squared forces (SOSF), and sum of squared moments (SOSM), are shown in Table 5.3. In the column labelled "source" are the possible sources of experimental deviation. "Opr" is the operator, "Bnh" is the bandwidth, "Opr*Bnh" is the interaction between the operator and bandwidth. "Error" indicates all other possible causes. The values in the column labelled "df" are the degrees of freedom in the sources. The sum of squares are computed from the data points. The mean square values are the sum of square values divided by the degrees of freedom. The F-ratio values are the mean square values divided by the mean square of the error. The last column is the "prob" ("probability"), column. The probability is the value of interest for this experiment.

For the results to be statistically significant at the $95 \%$ confidence level the "probability" value should be less than 0.05. For example, in the CT table, note that the values for the Opr, Bnh, and Opr*Bnh, are: $0.0,0.04,0.2139$. These values indicate that the CT varies with the operator (obviously), the bandwidth (which is what we were testing for), and that the interaction between operator and bandwidth has an insignificant effect on completion time. Similarly, the SOSF and SOSM show statistically significant variations with bandwidth. The statistical analysis also shows a strong variation of SOSF with the operator. This is not true for the SOSM. The interactions between operator and bandwidth for CT, SOSF, and SOSM, are not significant. The results of the ANOVA do not indicate which pairs of bandwidth values $(0.5$ and $1.0,0.5$ and 2.0 , and 1.0 and $2.0 \mathrm{~Hz})$ show significant 
variations in performance. The results of the procedure for this type of analysis are presented next.

There are several methods for such post hoc analysis. The method used in this study is Duncan's Multiple Range Test as described in Ott [1984]. The calculations are given in Appendix C. The results confirm what Figures $5.2 \mathrm{a}, \mathrm{b}$, and c indicate. The differences between the means of CT, SOSF, and SOSM corresponding to the 1 - and $2-\mathrm{Hz}$ bandwidth values are not significant. However, the differences between the $0.5-\mathrm{Hz}$ and $1.0-\mathrm{Hz}$ or $2.0-\mathrm{Hz}$ systems are significant.

Figure 5.3 (a, b, and c), the CT, SOSF, and SOSM vs. repetition, show little if any learning effect, indicating that the operators were well-trained. Therefore the assumption of no learning effects (Section 4.1) was correct. 


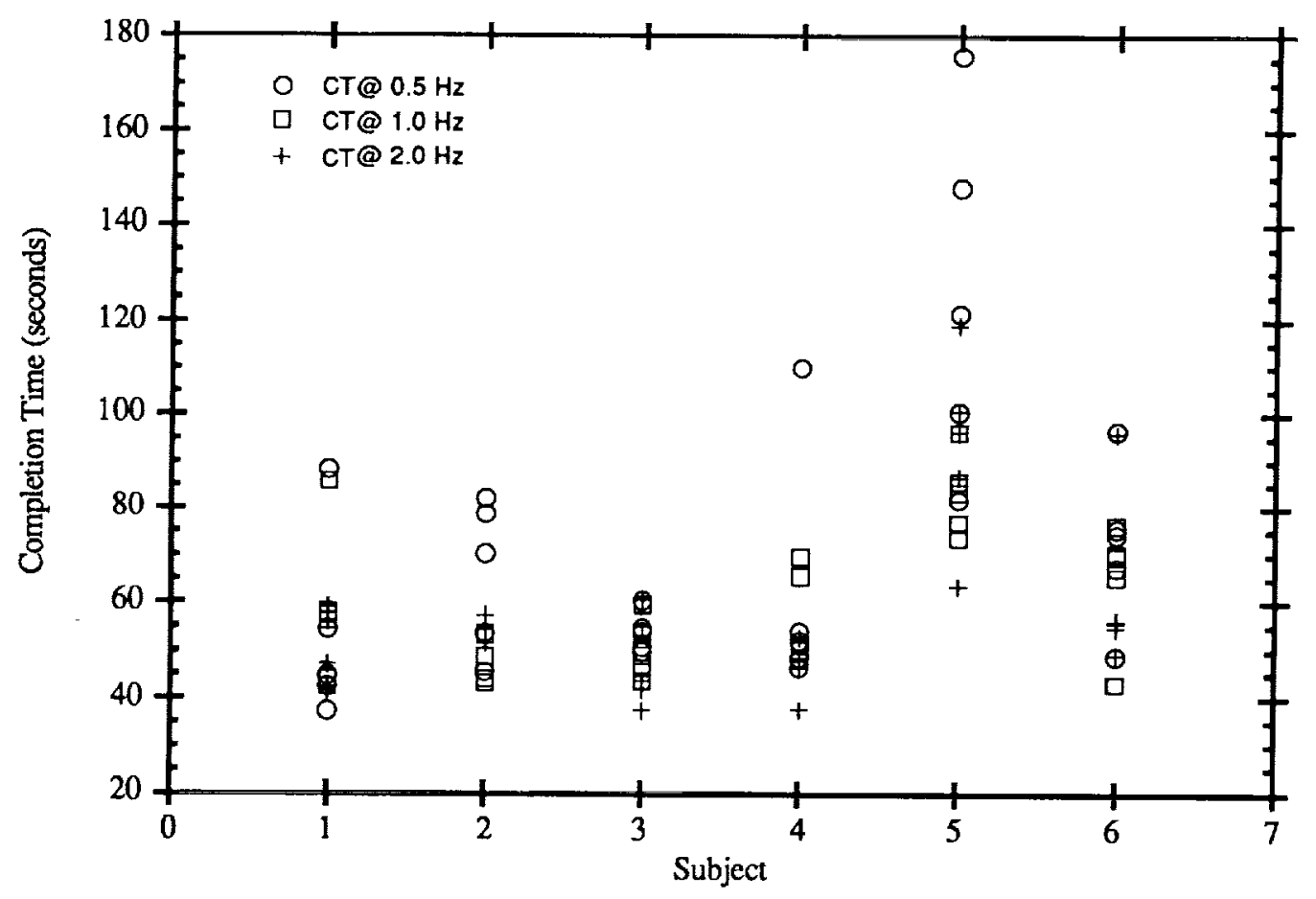

Figure 5.1a Completion Time vs. Subject 


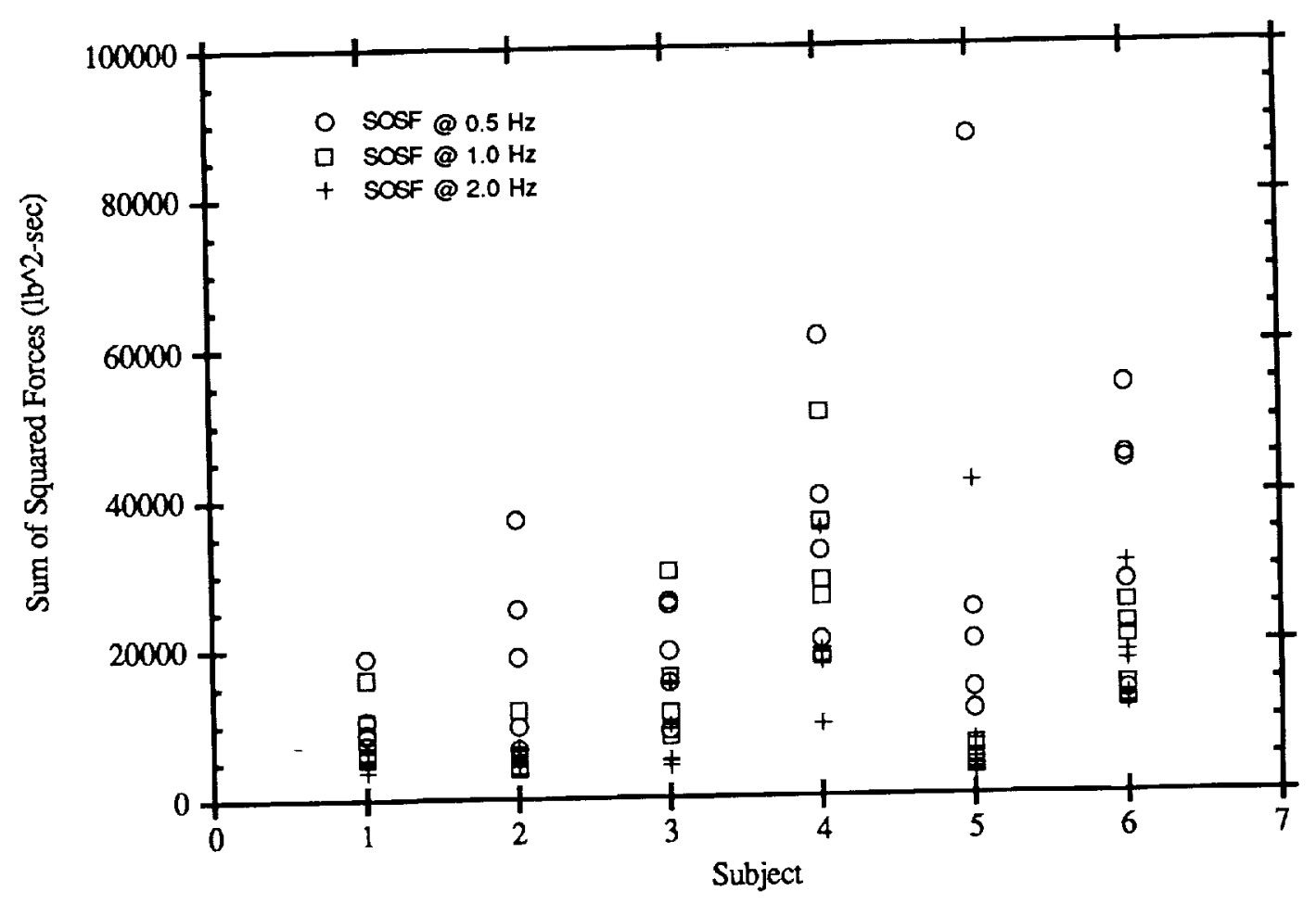

Figure 5.1b SOSF vs. Subject 


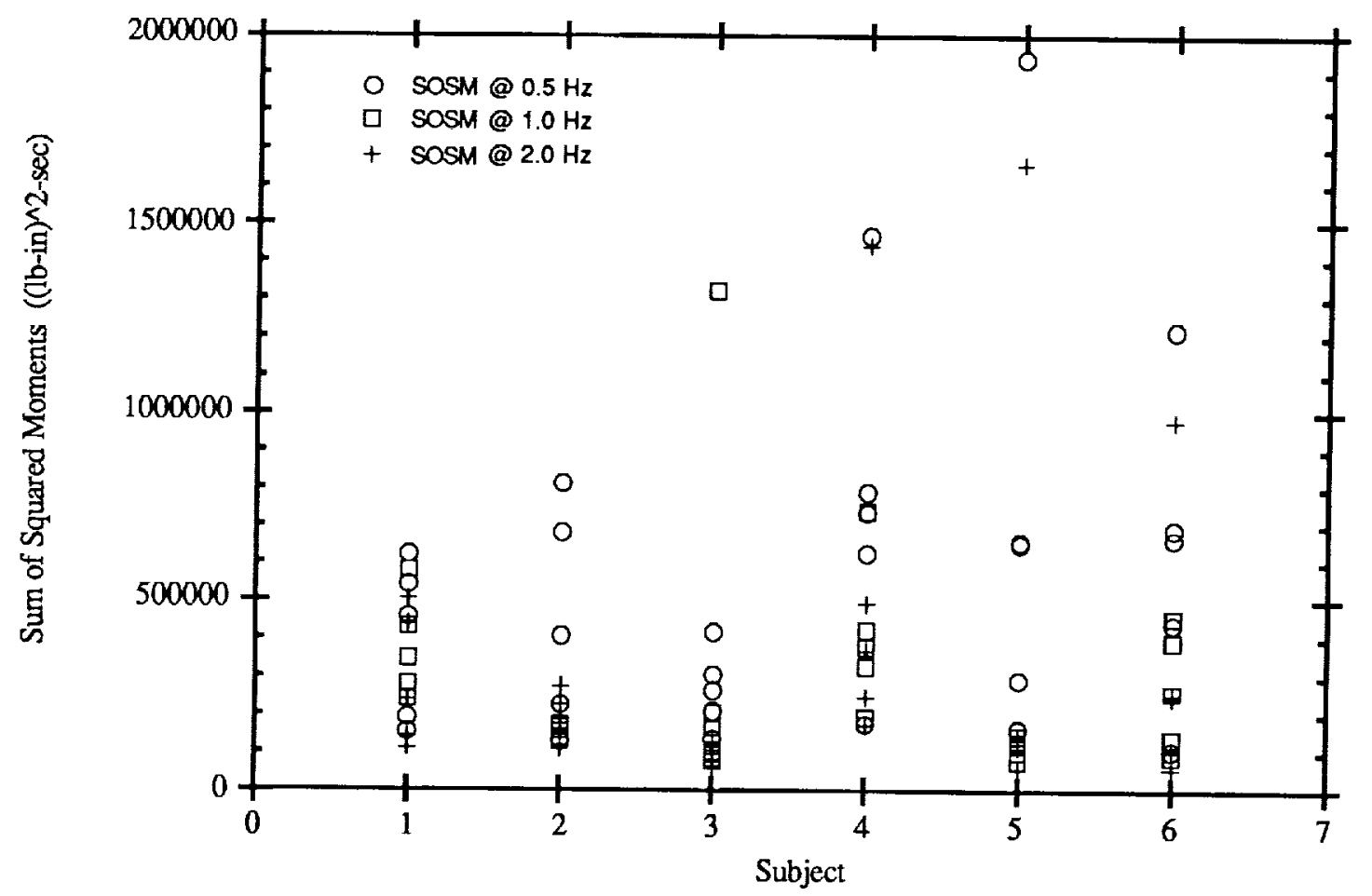

Figure 5.1c SOSM vs. Subject 
Table 5.1a Completion Time Statistics (seconds)

\begin{tabular}{|c|c|c|c|}
\hline & $0.5 \mathrm{~Hz}$ & $1.0 \mathrm{~Hz}$ & $2.0 \mathrm{~Hz}$ \\
\hline subject 1 & $\begin{array}{l}\text { mean: } 53.44 \\
\text { stddev: } 20.45\end{array}$ & $\begin{array}{l}\text { mean: } 57.304 \\
\text { stddev: } 17.408\end{array}$ & $\begin{array}{l}\text { mean: } 49.13 \\
\text { stddev: } 7.99\end{array}$ \\
\hline subject 2 & $\begin{array}{ll}\text { mean: } & 65.97 \\
\text { stddev: } & 15.83\end{array}$ & $\begin{array}{l}\text { mean: } 48.52 \\
\text { stddev: } 4.87\end{array}$ & $\begin{array}{ll}\text { mean: } & 54.64 \\
\text { stddev: } & 2.09\end{array}$ \\
\hline subject 3 & $\begin{array}{l}\text { mean: } 53.9 \\
\text { stddev: } 4.18\end{array}$ & $\begin{array}{l}\text { mean: } 50.38 \\
\text { stddev: } 6.25\end{array}$ & $\begin{array}{l}\text { mean: } 47.41 \\
\text { stddev: } 9.42\end{array}$ \\
\hline subject 4 & $\begin{array}{l}\text { mean: } 62.19 \\
\text { stddev: } 26.87\end{array}$ & $\begin{array}{l}\text { mean: } 57.08 \\
\text { stddev: } 9.74\end{array}$ & $\begin{array}{l}\text { mean: } 46.18 \\
\text { stddev: } 5.47\end{array}$ \\
\hline subject 5 & $\begin{array}{l}\text { mean: } 125.49 \\
\text { stddev: } 37.35\end{array}$ & $\begin{array}{l}\text { mean: } 83.26 \\
\text { stddev: } 8.82\end{array}$ & $\begin{array}{l}\text { mean: } 93.29 \\
\text { stddev: } 20.35\end{array}$ \\
\hline subject 6 & $\begin{array}{l}\text { mean: } 72.59 \\
\text { stddev: } 17.18\end{array}$ & $\begin{array}{l}\text { mean: } 65.05 \\
\text { stddev: } 12.86\end{array}$ & $\begin{array}{l}\text { mean: } 62.49 \\
\text { stddev: } 19.02\end{array}$ \\
\hline
\end{tabular}


Table 5.1b Sum of Squared Forces Statistics $\left(\mathrm{lb}^{\wedge} 2-\mathrm{sec}\right)$

\begin{tabular}{|c|c|c|c|}
\hline & $0.5 \mathrm{~Hz}$ & $1.0 \mathrm{~Hz}$ & $2.0 \mathrm{~Hz}$ \\
\hline subject 1 & $\begin{array}{l}\text { mean: } 10898 \\
\text { stddev: } 4619.2\end{array}$ & $\begin{array}{l}\text { mean: } 9163.5 \\
\text { stddev: } 4331.8\end{array}$ & $\begin{array}{l}\text { mean: } 5419 \\
\text { stddev: } 1390\end{array}$ \\
\hline subject 2 & $\begin{array}{ll}\text { mean: } & 19647 \\
\text { stddev: } & 12349\end{array}$ & $\begin{array}{l}\text { mean: } 6291.6 \\
\text { stddev: } 3250.4\end{array}$ & $\begin{array}{l}\text { mean: } 6021.6 \\
\text { stddev: } 979.03\end{array}$ \\
\hline subject 3 & $\begin{array}{l}\text { mean: } 19227 \\
\text { stddev: } 7220\end{array}$ & $\begin{array}{l}\text { mean: } 15103 \\
\text { stddev: } 9032\end{array}$ & $\begin{array}{l}\text { mean: } 7968 \\
\text { stddev: } 4801\end{array}$ \\
\hline subject 4 & $\begin{array}{l}\text { mean: } 35211 \\
\text { stddev: } 16705\end{array}$ & $\begin{array}{l}\text { mean: } 32418 \\
\text { stddev: } 12330\end{array}$ & $\begin{array}{l}\text { mean: } 20483 \\
\text { stddev: } 9514\end{array}$ \\
\hline subject 5 & $\begin{array}{ll}\text { mean: } & 31828 \\
\text { stddev: } & 31826\end{array}$ & $\begin{array}{l}\text { mean: } 4869.6 \\
\text { stddev: } 1230.8\end{array}$ & $\begin{array}{lc}\text { mean: } & 11960 \\
\text { stddev: } & 16835\end{array}$ \\
\hline subject 6 & $\begin{array}{l}\text { mean: } 37265 \\
\text { stddev: } 16199\end{array}$ & $\begin{array}{l}\text { mean: } 19253 \\
\text { stddev: } 5517\end{array}$ & $\begin{array}{l}\text { mean: } 18530 \\
\text { stddev: } 7496\end{array}$ \\
\hline
\end{tabular}


Table 5.1c Sum of Squared Moments Statistics ((lb-in)^2-sec)

\begin{tabular}{|c|c|c|c|}
\hline & $0.5 \mathrm{~Hz}$ & $1.0 \mathrm{~Hz}$ & $2.0 \mathrm{~Hz}$ \\
\hline subject 1 & $\begin{array}{l}\text { mean: } 394177 \\
\text { stddev: } 209676\end{array}$ & $\begin{array}{l}\text { mean: } 377602 \\
\text { stddev: } 134650\end{array}$ & $\begin{array}{l}\text { mean: } 288236 \\
\text { stddev: } 176309\end{array}$ \\
\hline subject 2 & $\begin{array}{l}\text { mean: } 451568 \\
\text { stddev: } 290666\end{array}$ & $\begin{array}{lr}\text { mean: } & 155956 \\
\text { stddev: } & 17222\end{array}$ & $\begin{array}{lr}\text { mean: } & 188590 \\
\text { stddev: } & 67384\end{array}$ \\
\hline subject 3 & $\begin{array}{l}\text { mean: } 266351 \\
\text { stddev: } 105271\end{array}$ & $\begin{array}{l}\text { mean: } 376641 \\
\text { stddev: } 530943\end{array}$ & $\begin{array}{l}\text { mean: } 95946 \\
\text { stddev: } 28588\end{array}$ \\
\hline subject 4 & $\begin{array}{l}\text { mean: } 758894 \\
\text { stddev: } 463579\end{array}$ & $\begin{array}{l}\text { mean: } 413390 \\
\text { stddev: } 201169\end{array}$ & $\begin{array}{l}\text { mean: } 54562 \\
\text { stddev: } 515362\end{array}$ \\
\hline subject 5 & $\begin{array}{ll}\text { mean: } & 740669 \\
\text { stddev: } & 704252\end{array}$ & $\begin{array}{lr}\text { mean: } & 116884 \\
\text { stddev: } & 25637\end{array}$ & $\begin{array}{l}\text { mean: } 422489 \\
\text { stddev: } \quad 692340\end{array}$ \\
\hline subject 6 & $\begin{array}{l}\text { mean: } 624615 \\
\text { stddev: } 406200\end{array}$ & $\begin{array}{l}\text { mean: } 269375 \\
\text { stddev: } 157642\end{array}$ & $\begin{array}{l}\text { mean: } 329805 \\
\text { stddev: } 373416\end{array}$ \\
\hline
\end{tabular}




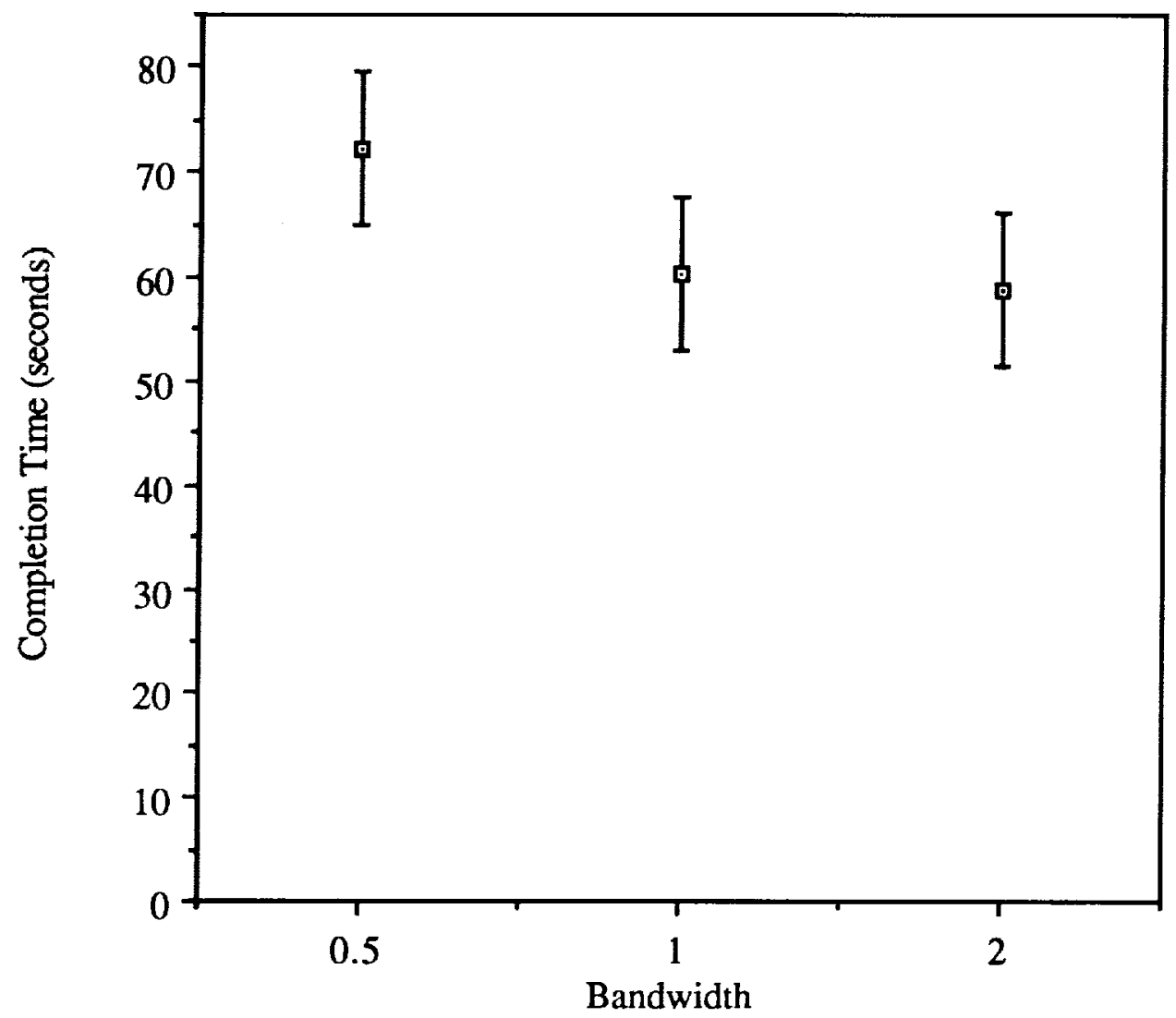

Figure 5.2a Completion Time vs. Bandwidth for all operators and repetitions

Table 5.2a Data for figure 5.2a

Bandwidth (Hz)
0.5
1.0
2.0

Mean CT (seconds)

72.261

60.266

58.857

Standard Deviation

32.552

15.363

20.228 


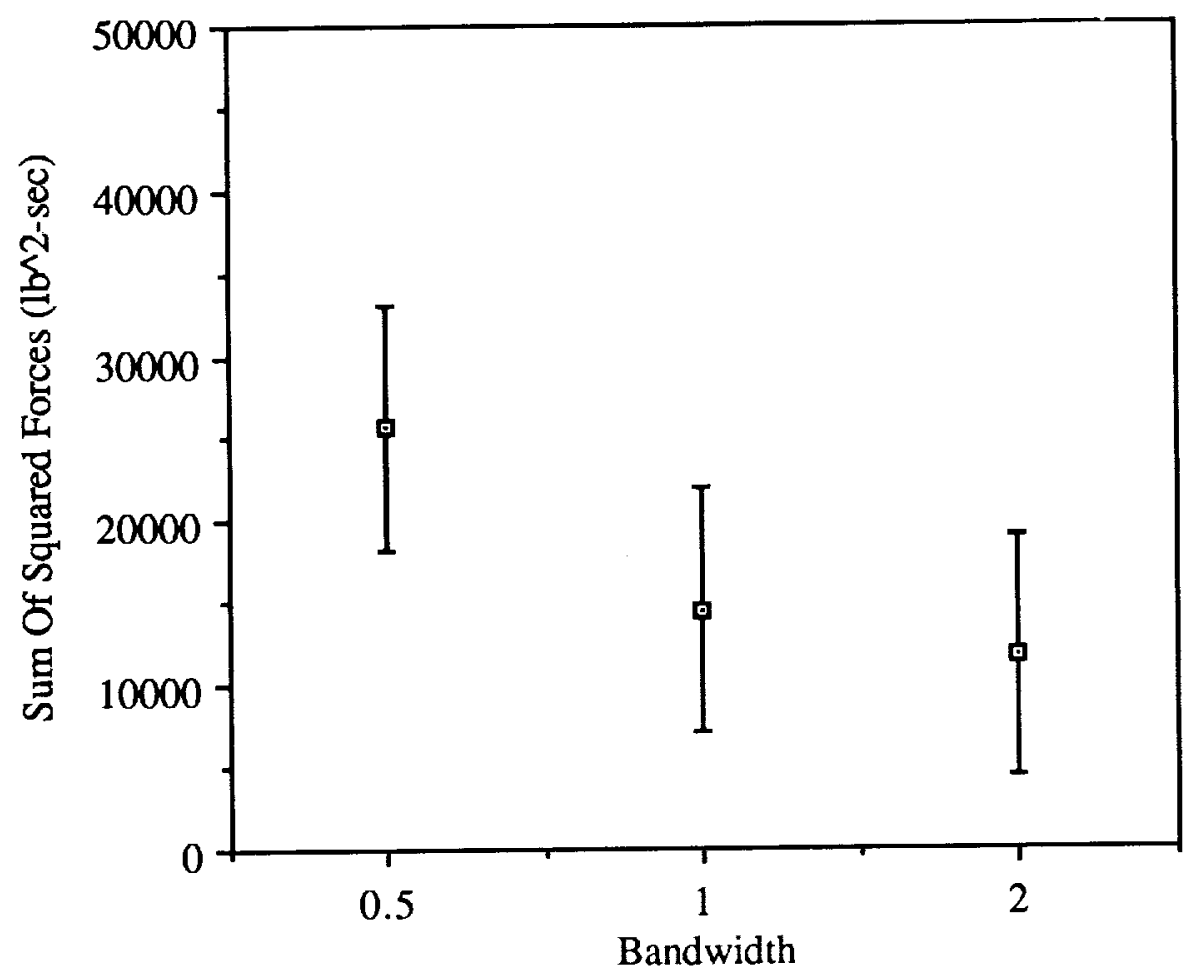

Figure 5.2b SOSF vs. Bandwidth for all operators and repetitions

Table 5.2b Data for figure $5.2 \mathrm{~b}$

Bandwidth (Hz)

0.5

1.0

Mean SOSF $\left(\mathrm{lb}^{\wedge} 2\right.$-sec $)$ 25680

14517

Standard Deviation 18494

11511

2.0

11731

9951 


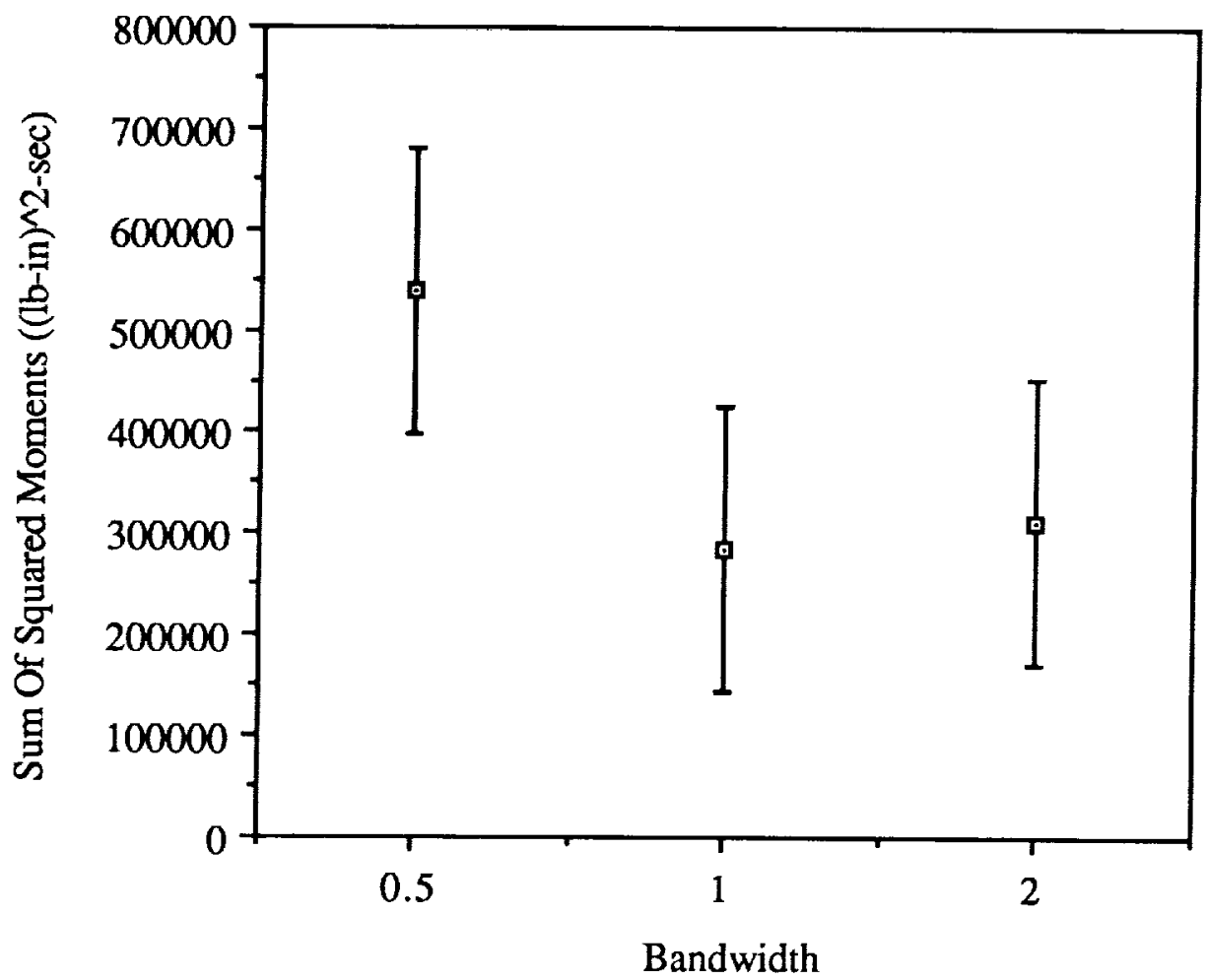

Figure 5.2c SOSM vs. Bandwidth for all operators and repetitions

Table 5.2c Data for figure 5.2c

$\begin{array}{ccc}\text { Bandwidth (Hz) } & \text { Mean } \text { SOSM((lb-in)^2-sec) }^{\wedge} & \text { Standard Deviation } \\ 0.5 & 539379 & 417636 \\ 1.0 & 284975 & 253140 \\ 2.0 & 311705 & 386411\end{array}$


Table 5.3 ANOVA Results

\section{Completion}

Time (CT)

$\begin{array}{llllll}\text { Source } & \text { df } & \text { Sum of Squares } & \text { Mean Square } & \text { F-ratio } & \text { Prob } \\ \text { Opr } & 5 & 26762.5 & 5252.50 & 20.217 & 0.000 \\ \text { Bnh } & 2 & 3255.06 & 1627.53 & 4.5023 & 0.0403 \\ \text { Opr*Bnh } & 10 & 3614.92 & 361.492 & 1.3654 & 0.2139 \\ \text { Error } & 72 & 19062.6 & 264.758 & & \\ \text { Total } & 89 & 52695.1 & & & \end{array}$

Sum of

Squared

Forces

(SOSF)

\section{Source}

Opr

Bnh

$\mathrm{Opr} * \mathrm{Bnh}$

Error

Total

$\begin{array}{ll}\text { df } & \text { Sum of Squares } \\ 5 & 5076056022 \\ 2 & 3269486474 \\ 10 & 1431721641 \\ 72 & 10125316688 \\ 89 & 19902580824\end{array}$

Mean Square

1015211204

1634743237

143172164

140629398
F-ratio

7.2191

11.418

1.0181
Prob

0.000

0.0026

0.4371

\section{Sum of}

Squared

Moments

(SOSM)

$\begin{array}{llllll}\text { Source } & \text { df } & \text { Sum of Squares } & \begin{array}{l}\text { Mean Square } \\ \mathrm{e}+11\end{array} & \begin{array}{l}\text { F-ratio } \\ 1.6820\end{array} & \begin{array}{l}\text { Prob } \\ \text { Opr }\end{array} \\ \text { Bnh } & 2 & 1 \mathrm{e}+12 & 1 \mathrm{e}+12 & 6 \mathrm{e}+149 \\ \text { Bnh } & 10 & 1 \mathrm{e}+12 & 96062587931 & 6.1039 & 0.0185 \\ \text { Opr*Bnh } & 72 & 9 \mathrm{e}+12 & 1 \mathrm{e}+11 & & 0.6745 \\ \text { Error } & 89 & 1 \mathrm{e}+13 & & & \\ \text { Total } & & & & & \end{array}$




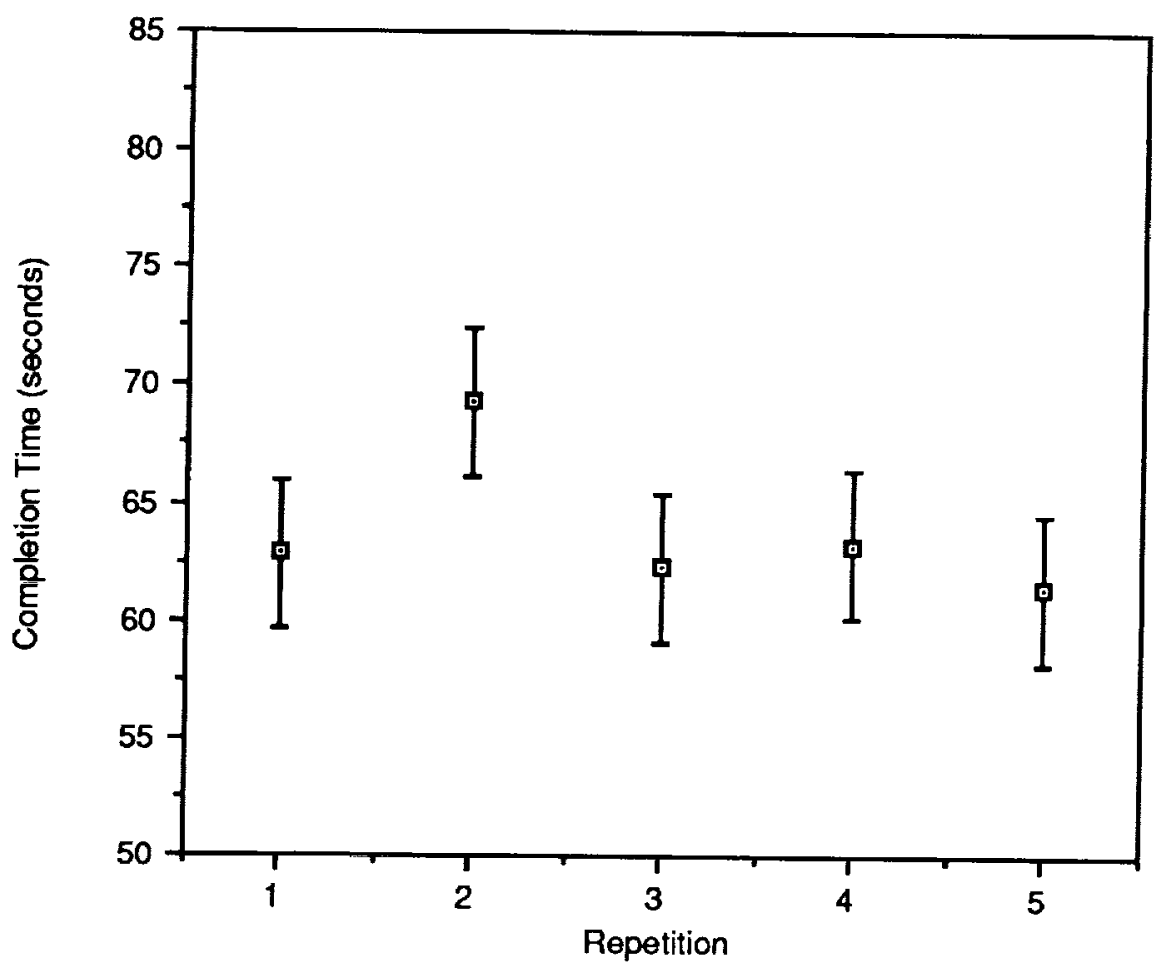

Figure 5.3a CT vs. Repetition for all subjects 


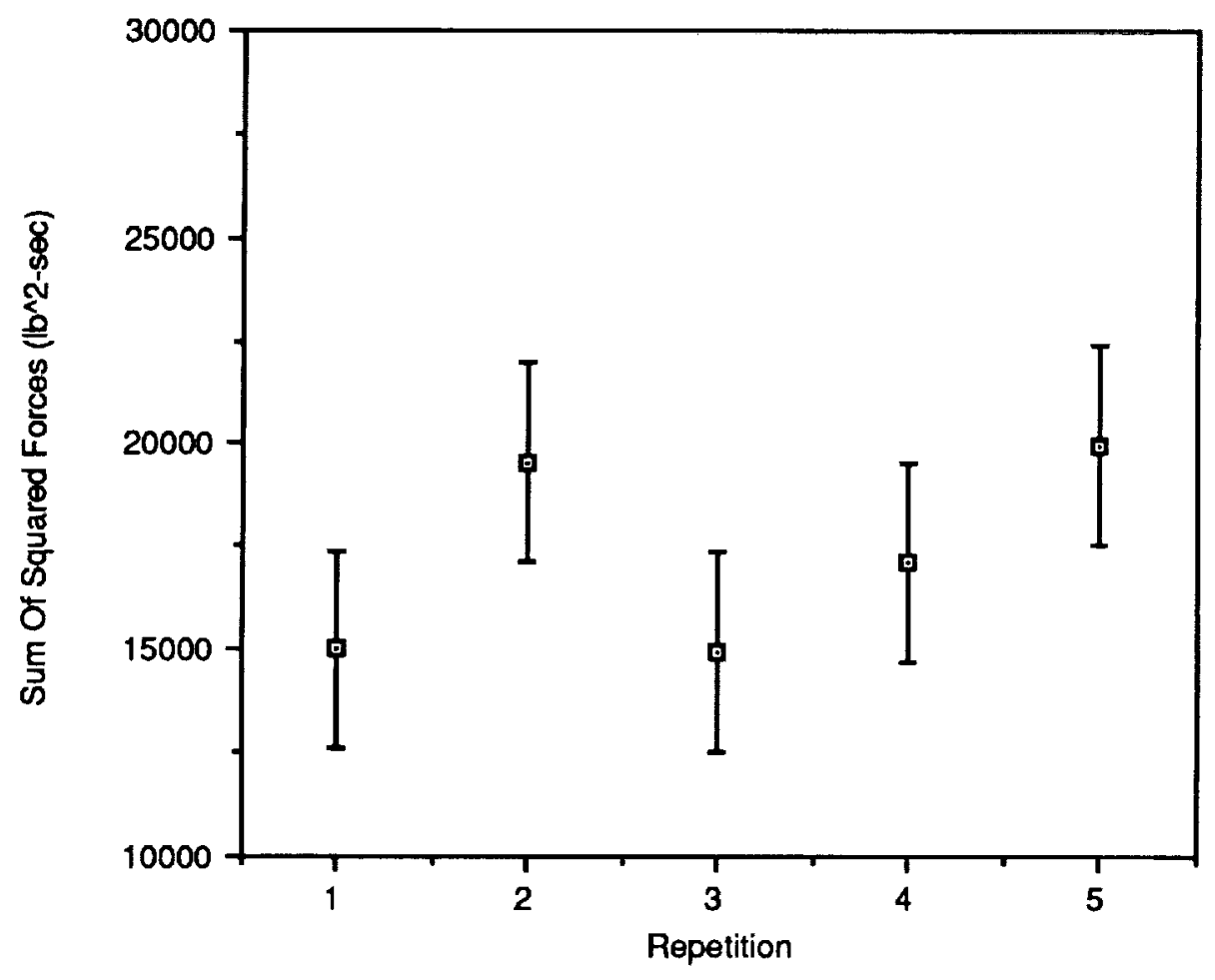

Figure 5.3b SOSF vs. Repetition for all subjects 


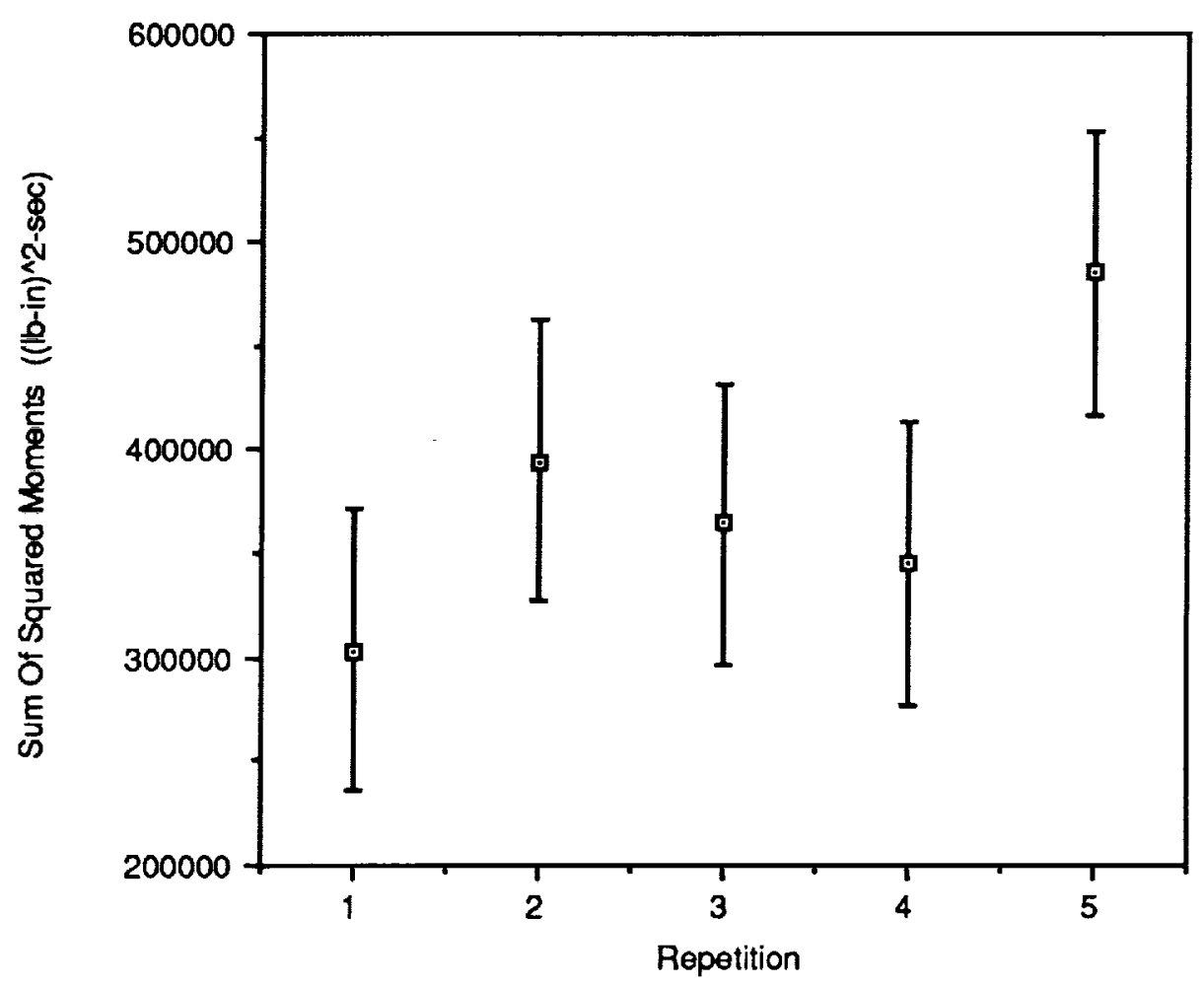

Figure 5.3c SOSM vs. Repetition for all subjects 


\subsection{Discussion}

Critical arguments that justify the results are provided below.

The first factor considered is completion time. The completion time decreases as the joint position bandwidth increases from 0.5 to 1 to $2 \mathrm{~Hz}$. We therefore expect that the CT will decrease with increasing bandwidth if a significant amount of free-space travel is required in the task. This expectation holds true between the $0.5-$ and $1-\mathrm{Hz}$ system. Surprisingly, the CT does not decrease significantly as the joint bandwidth increases from 1 to $2 \mathrm{~Hz}$.

One possible explanation is that the operator commands positions with maximum frequency components between 1 and $2 \mathrm{~Hz}$. This explanation implies that the $2-\mathrm{Hz}$ bandwidth would not decrease the CT. These results agree qualitatively with those in Book and Hannema [1980] and Kim et al. [1987]. Both of these studies indicate an exponentially decreasing CT with increasing joint bandwidth. The curves approach their asymptotic values near $3 \mathrm{~Hz}(+/-0.5 \mathrm{~Hz})$. It is possible that our experiment did not have enough resolution to discern the increase in performance between the 1and $2-\mathrm{Hz}$ systems.

Another possible explanation is that operator spent more time inserting and removing the peg in the 0.5 $\mathrm{Hz}$ system. The force/torque data records contain the information required to determine the insertion/removal times.

The next factors considered are the SOSF and SOSM. The experimental data shows a large decrease in SOSF and SOSM between the $0.5 \mathrm{~Hz}$ and $1 \mathrm{~Hz}$ systems, and little difference between the 1 and $2 \mathrm{~Hz}$ systems. We analyze this data using a model of an impedance controlled manipulator in contact with a stiff environment recently developed by Kim and Bejczy [1990]. The details of this analysis are given in Appendix B. The analysis indicates that that the $0.5 \mathrm{~Hz}$ system is marginally stable. This situation would result in relatively large forces exerted on the environment due to the long settling time of the impedance loop. In contrast, the 1 and $2 \mathrm{~Hz}$ systems have nearly the same phase margin, so we would expect their responses to be nearly the same. The data agree with this hypothesis.

The final observation is about the SOSM. The ANOVA (the "Prob" column in the "Opr" row of Table 5.3 for SOSM) indicates that the SOSM is independent of the operator. This is in direct contrast with the CT and SOSF, which are strongly dependent on the operators. Currently, there is no explanation for this result.

\subsection{CONCLUSIONS AND FURTHER RESEARCH}

The main purpose of this study was to determine the effect the slave manipulator joint bandwidths on telerobot performance. Our results indicate that lowering the bandwidth from 1 or $2 \mathrm{~Hz}$ to $0.5 \mathrm{~Hz}$ impairs system performance.

One concern is the issue of applicability of these results to other systems with different dynamic characteristics. In particular, an arm with different contact characteristics (such as the DTF-1 manipulator) may yield different results for a similar set of experiments. The differences would most likely appear in the forces exerted on the environment since they are highly dependent on contact characteristics.

Currently, the DTF-1 manipulator has design specifications of $1-\mathrm{Hz}$ joint bandwidth, a damping ratio of 0.707 and approximately $5-\mathrm{lbs} / \mathrm{in}$ Cartesian stiffness without an impedance loop. The system used in this experiment, in contrast, required an impedance filter to give the slave arm the same Cartesian stiffness. The trade-off was that the impedance filter required a large damping constant to maintain system stability. The Cartesian response of the experimental system in contact with the environment is 
therefore different from that of the proposed DTF-1 manipulator. In the future, we will have to make our Cartesian impedance equivalent to that proposed for DTF-1 or FTS in order to make comparisons between the two systems. Changing the contact performance may require using a higher joint bandwidth so that a higher bandwidth impedance filter can be used. This implies a direct trade-off between the free-space motion equivalence and the contact impedance equivalence.

Results of this study also show that validating "improvements" to the telerobot system requires valid statistical experimentation and analysis using objective measures of performance. The CT, SOSF, and SOSM are three such measures.

It must be pointed out that the performance of a telerobot system is a function of the operator, the master, the slave, the environment, and their interactions. Any change in one of these factors has to be evaluated in terms of its impact on the total system.

There are still several questions which remain from this study. The effect of the impedance filter on the Cartesian bandwidths and contact response of the manipulator should be examined. Partitioning the force records would allow evaluation of the measures for the distinct phases of the task (e.g., free space movement, insertion, removal, etc.). There may be some advantage in using Fourier domain analysis of the force/torque records. Another topic for study is the effect of various bandwidths with the impedance filter optimized for that bandwidth. Experiments using more complex tasks are needed to make realistic extrapolations of the results to actual space flight scenarios. 


\subsection{REFERENCES}

An, C. and J. Hollerbach, 1987, "Dynamic Stability Issues in Force Control of Manipulators," Proceedings IEEE 1987 International Conference on Robotics and Automation.

Brooks, T., 1990a, "Telerobotic Response Requirements," Proceedings 1990 IEEE Conference on Systems, Man, and Cybernetics.

Brooks, T., 1990b, "Tele-Robot Response Requirements - A Position Paper on Control Response Requirements for the FTS Tele-Robot," ST Systems Corp. STX/ROB/90-03, Lanham, MD.

Book, W. and Dirk P. Hannema, 1980, "Master-Slave Manipulator Performance for Various Dynamic Characteristics and Positioning Task Parameters," IEEE Transactions on Systems, Man and Cybernetics, Vol SMC-10, No. 11, pp. 764-771.

Draper, J., J. Herndon, B.Weil, and W. Moore, 1987, "Effects of Force Reflection on Servomanipulator Task Performance," Proceedings of the American Nuclear Society's International Topical Meeting on Remote Handling and Robotics in Hostile Environments.

Hannaford, B. and L. Wood, 1989, "Performance Evaluation of a 6-Axis High Fidelity Generalized Force Reflecting Tele-Operator," Proceedings Nasa Conference on Space Robotics, Pasadena CA.

Kim, Won S. and A. K. Bejczy, 1990, "A Stability Analysis of Shared Compliance Control," Proceedings of Japan-USA Symposium on Flexible Automation.

Kim, Won S., Frank Tendick, Stephen R. Ellis, and Lawrence Stark, 1987, “A Comparison of Position and Rate Control for Telemanipulations with Consideration of Manipulator System Dynamics," IEEE Journal of Robotics and Automation, Vol RA-3, No. 5, pp. 426-436.

Leake, S., 1990, "FTS Tele-operation Algorithms - Definitions and Implementation," NASA Internal Memo, NASA Goddard Space Flight Center, Greenbelt MD.

Molino, J., 1990, "Evaluating Preliminary Flight Procedures for the Flight Tele-Robotic Servicer," Tech-U-Fit Corp TUF 90-03 for NASA GSFC Robotics Lab Code 735.1, Alexandria, VA.

Ott, Lyman, 1984, An Introduction to Statistical Methods and Data Analysis, PWS publishers, Boston, MA.

Vassoughi, R., and M. Donath, 1990, "Using Impedance Controlled Robots for Simulating Manipulation Tasks Occurring in a Gravityless Environment," Proceedings 1990 IEEE Conference on Robotics and Automation, pp. 62-68. 


\section{Appendix A: Telerobot System Parameters}

1. Motion Mapping: This feature determines whether master rates or positions are mapped to slave rates or positions. Three combinations are useful: Position-Position (Pose-Pose), Rate-Rate, and Position-Rate. The first two are theoretically the same, but differ in implementation. The last one performs similarly to a "joystick," This study used pose-pose mapping in which master positions map to slave positions using forward and inverse kinematics.

2. Motion Scaling: This option specifies the ratio of master to slave displacements for pose-pose mapping. A similar ratio exists for the other two mappings. The motion scale can be set independently for all 3 translation and 3 rotation components. A value of 4:1 was selected (see Section 4.3).

3. Motion Frame: The motions of the master are measured with respect to a coordinate system fixed to the hand grip of the master controller. The possible frames include: an object frame located arbitrarily on the end-effector, a camera frame located in one of several camera views, etc. In these experiments, the coordinate frame was located at the tip of the peg.

4. Indexing: Indexing allows the operator to deactivate the master controller so that it may be reoriented. The master commands are then issued for movement relative to the reoriented position. Indexing was available and necessary for the present experiments because of the large-scale motions involved.

5. Axis Selection: Axis selection allows masking of motion commands from the master along any of the axes of motion. For example, the operator can disable all rotations, in which case, the end effector would maintain its orientation and would only change position in response to commands from the master. The impedance filter is still active in this mode. These experiments did not use masking.

6. Axis Frame: Determines the location of the disabled axis frame. The frames available are the motion frames.

7. Force Reflection: Forces measured by the force/torque sensor can be reflected back to the master controller. The maximum force which the master can generate is $5 \mathrm{lbf}$. The frames for the measured and reflected forces are determined by the motion frames. Force reflection was enabled for these experiments.

8. Force Reflection Scaling: This option specifies the ratio of force measured at the slave to force commanded to the master. A value of $30: 1$ was selected (see Section 4.3).

9. Impedance Stiffness and Damping: The impedance loop feeds back the signals from the force/torque sensor to adjust the slave position commands from the master. This feature gives the slave arm an adjustable compliance during contact with the environment. A stiffness of 5 lbf/inch (850 $\mathrm{N} / \mathrm{cm}$ ) was used in these experiments. The section on setting and verification of parameters discusses the selection of the value for this factor. The impedance damping was set to $346 \mathrm{lbf} / \mathrm{inch} / \mathrm{sec}(65000$ $\mathrm{N} / \mathrm{m} / \mathrm{s}$ ) (see Section 4.3). 


\section{Appendix B: Explanation of SOSF and SOSM Results}

Consider the model in figure B.1. This is a model of the impedance loop in the slave manipulator, not the entire operator/force feedback loop.

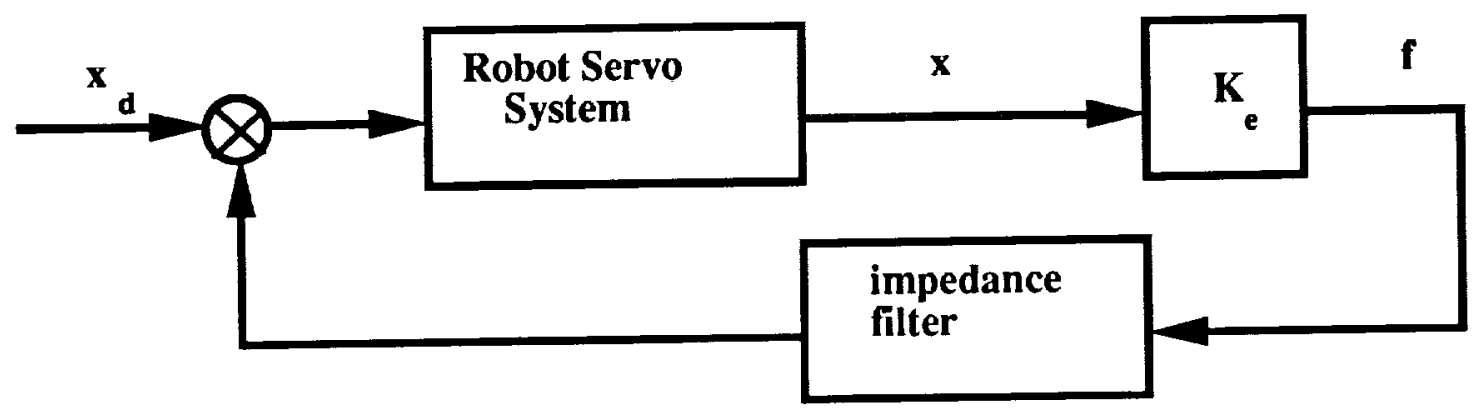

Figure B.1 Block diagram model of impedance control

Generating the transfer functions for the model requires two assumptions. It can be shown (Kim and Bejczy [1990], Vassughi and Donath [1990]) that the Cartesian dynamics of a manipulator are a parallel combination of joint dynamics. For our system, all joints have the same selected bandwidth. The Cartesian bandwidth is therefore equivalent to the joint bandwidth. For example, when the joint bandwidths are set at $1 \mathrm{~Hz}$, we can assume that the Cartesian bandwidth is $1 \mathrm{~Hz}$. The other assumption is that the environmental spring constant, $\mathrm{Ke}$, is the stiffness of the robot. This assumption is reasonable if the environment (in this case the task panel) is very stiff relative to the robot. Figure B. 2 shows the approximate values for a $1-\mathrm{Hz}$ system similar to that used in our tests. The impedance filter in Figure B.2 has the same value as the experimental filter. Experiments are underway to verify the Cartesian stiffness (Ke) and the Cartesian bandwidth of the RRC arms.

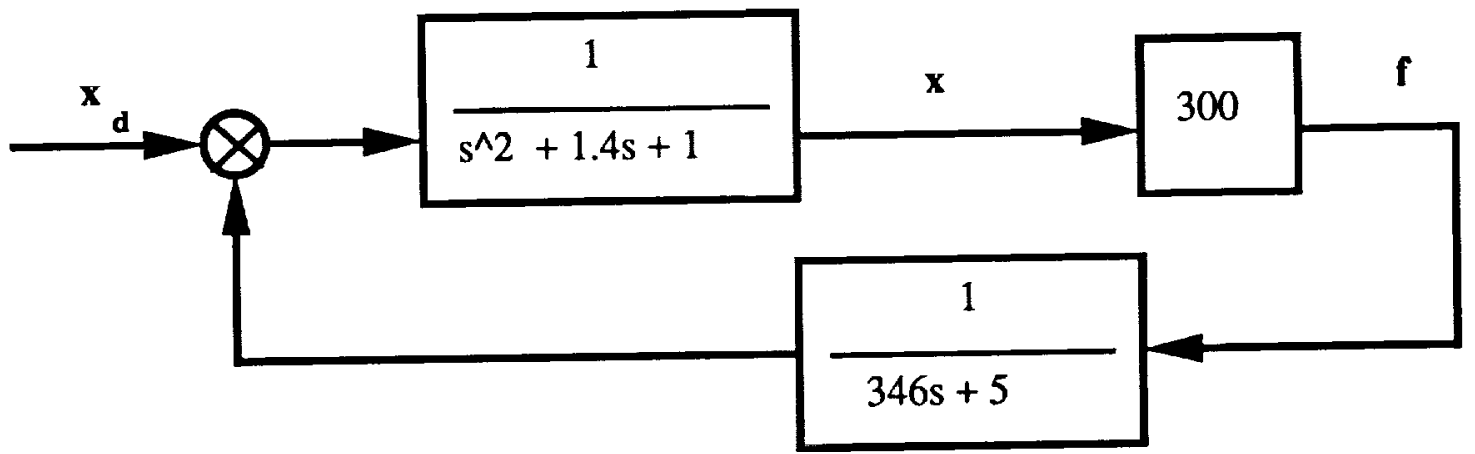

Figure B.2 Example of a $1 \mathrm{~Hz}$ arm with impedance filter and Ke similar to the one used in our tests

Figure B.3 a, b, and c show Bode plots of the system for Cartesian bandwidths of 0.5, 1.0, and 2.0 $\mathrm{Hz}$. [Note: if the Cartesian servo transfer function is $\mathrm{G}$, and the impedance filter is $\mathrm{H}$, then the Bode plots are for the function $\mathrm{KeGH}$. These Bode plots show that the $0.5-\mathrm{Hz}$ system is marginally stable (phase margin equal to 0 degrees). The comparison with the 1 and $2 \mathrm{~Hz}$ systems is the point of interest. The 1 -and $2-\mathrm{Hz}$ systems have phase margins of 25 degrees and 28 degrees, respectively. Clearly, both systems have an acceptable damping ratio. 

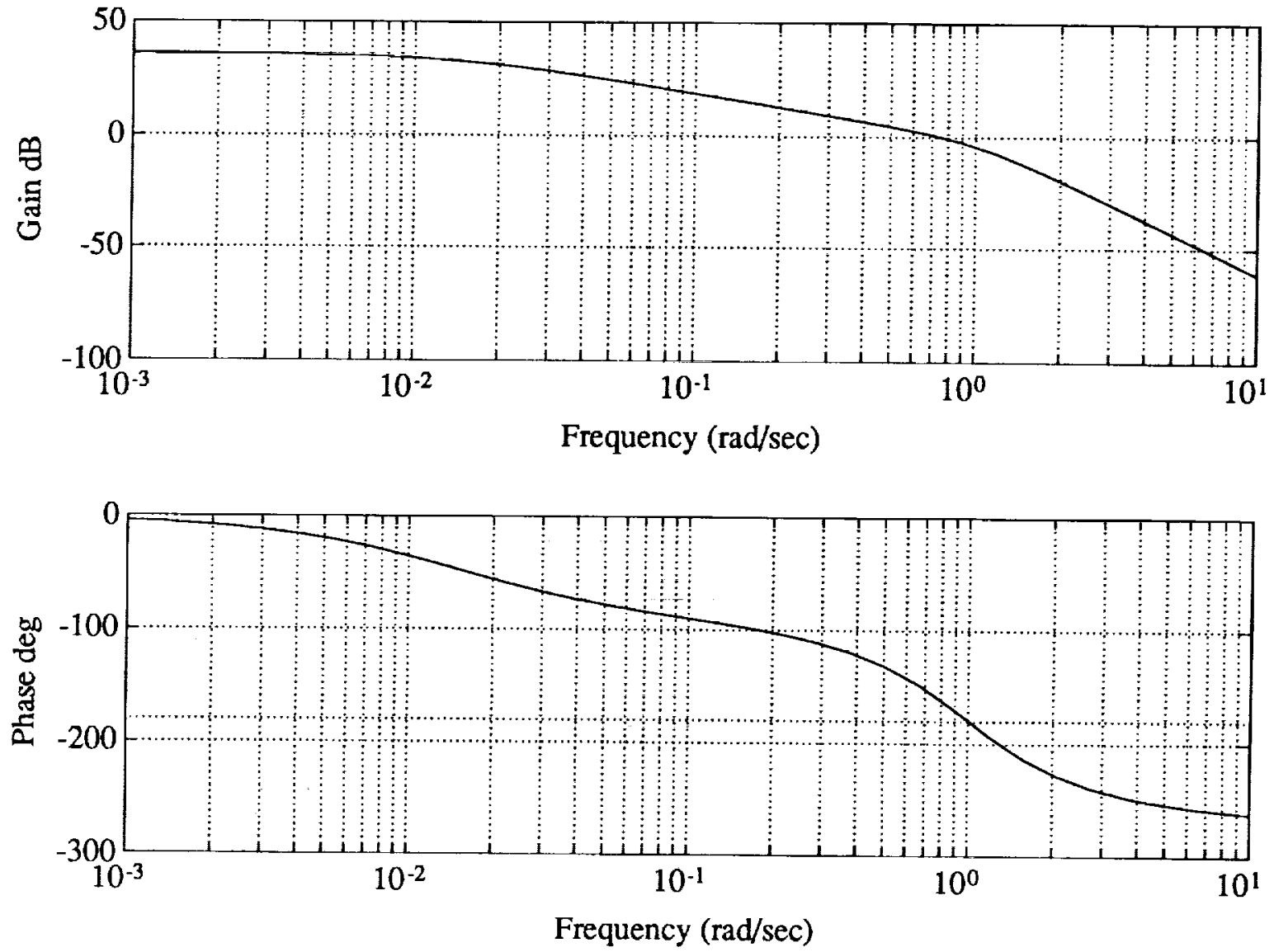

Figure B.3b 

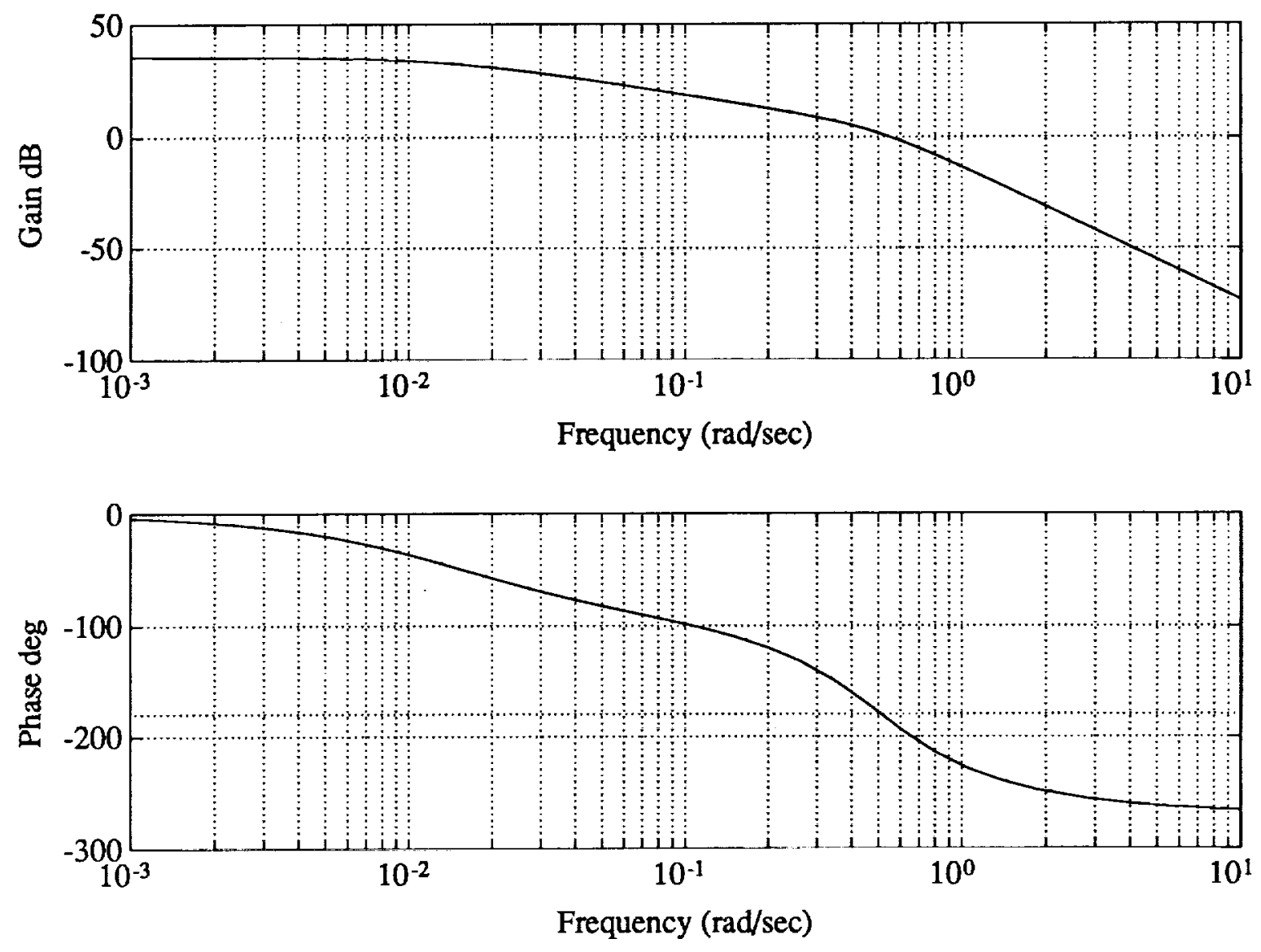

Figure B.3a 

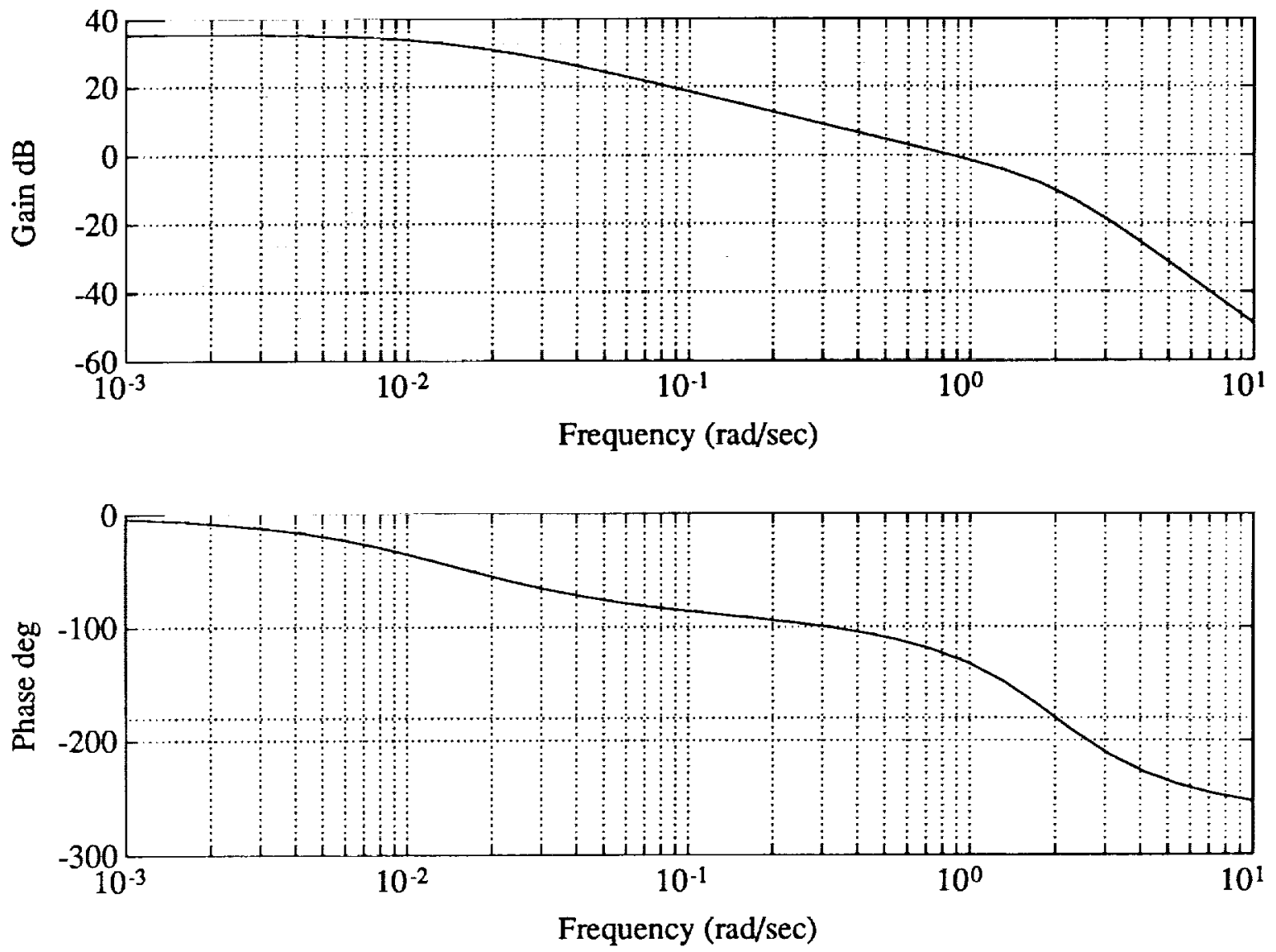

Figure B.3c 


\section{Appendix C: Post Hoc Analysis}

There are several methods for post hoc analysis of data. The method used here is Duncan's Multiple Range Test, described in Ott [1984]. As an example, follow the analysis for completion time. In the row labelled "means" are the mean values of the completion times at the three bandwidths shown in the row labelled "bandwidth." Clearly, there are differences between the mean values. The question is whether the differences are statistically significant. There are three possible combinations of differences: 0.5 and $1.0 \mathrm{~Hz}, 0.5$ and $2.0 \mathrm{~Hz}$, and 1.0 and $2.0 \mathrm{~Hz}$. These combinations are shown in the row marked "combinations." The differences between the mean CTs are in the "difference between means" row. Between the "combinations" row and the "difference between means" row are the intermediate calculations required to produce the value in the row marked "W'r." If the difference between the means is significant, the difference has to be greater than the "W'r" value in the same column. For CT we see that the differences between mean CTs at 0.5 and 1.0 , and 0.5 and $2.0 \mathrm{~Hz}$ are significant as opposed to the differences between mean CTs at 1.0 and $2.0 \mathrm{~Hz}$. The results are similar for the SOSF and SOSM. 


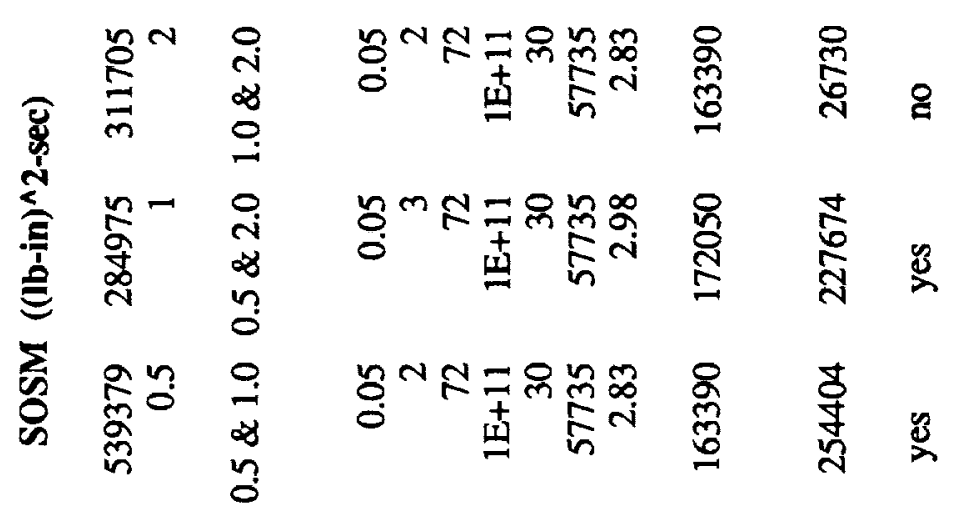

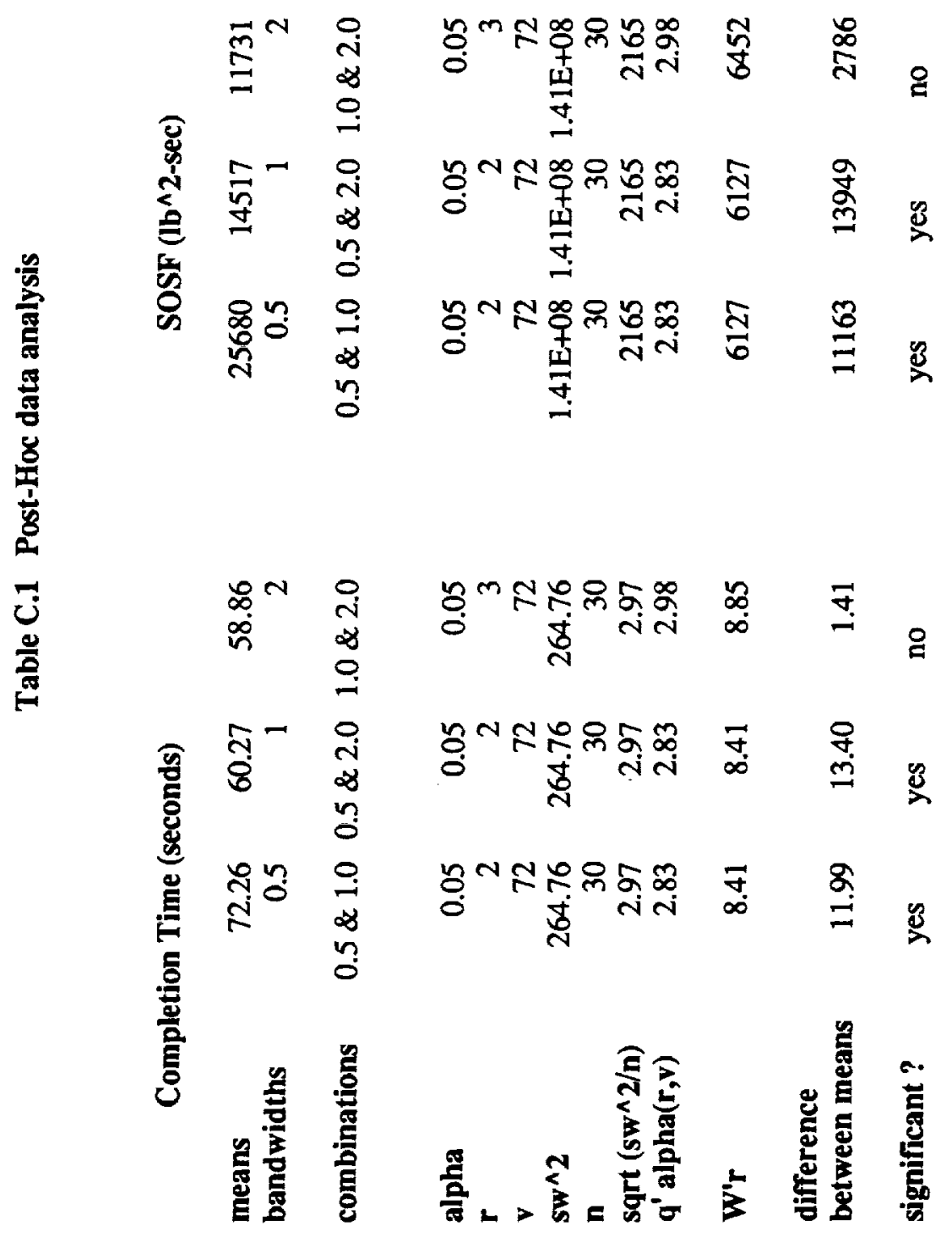




\section{Appendix D: Experiment Script for Bandwidth Testing}

I. Observer-Initialize system
A. Save previous days metrics data on Mac to tape drive
B. Turn on master, slave, PC, Multibus, Mac
C. Download code to Multibus
D. Start PC code, start data collection program on Mac
E. Initialize slave (enable, home, etc.)
F. Set master/slave parameters that are constant on PC
a. Motion mapping $=$ Pose - Pose
b. Motion frame $=$ Object
c. Axis selection $=$ On (for all axes)
d. Axis frame $=$ Object
e. Force reflection scaling $=30: 1$ (translation and rotation)
f. Position scaling $=4: 1$ (translation and rotation)
g. Slave stiffness $=5 \mathrm{lb} / \mathrm{in}$. (rranslation and rotation)
$\mathrm{h}$. Slave damping $=350 \mathrm{lb}^{*} \mathrm{~s} / \mathrm{in}$. (translation and rotation)
G. Put robot in start configuration relative to task panel

II. Tests

A. Operator seated at station

B. $\overline{\overline{O b s e r v e r}}$ selects test number from hat

C. Observer sets bandwidth on PC in accordance with test number

a. Test $1 \Rightarrow$ Bandwidth $=0.5 \mathrm{~Hz}$

c. Test $3 \Rightarrow$ Bandwidth $=1.0 \mathrm{~Hz}$

e. Test $5 \Rightarrow$ Bandwidth $=2.0 \mathrm{~Hz}$

D. Observer types operator initials, test number, and repetition number into Mac

E. Observer selects "begin test" on Mac

F. Operator activates master

G. Observer instructs operator: "You are to perform the task as quickly as possible while exerting minimum force on the environment. The completion time and force applied are both weighted equally. Maintain a light to medium grasp on the master. The task starts and ends with tapping the target next to the hole."

I. Operator does peg-in-hole task

a. Tap panel at home square with tip of peg

(Note: Observer should verify tap detected on Mac)

b. Insert peg to bottom of hole

c. Remove peg from hole

d. Tap panel at home square with tip of peg

J. Operator deactivates master

K. Observer conducts post-test interview

L. Operator and Observer wait for Mac program to complete

M. Goto II B. for each test per operator

N. Goto II B. for 5 repetitions of each set of tests

III. Observer end-of-day shut-down of system
A. Download raw data to tape drive
B. Process data to compute metrics (this program runs overnight)
C. Turn off sensitive equipment 


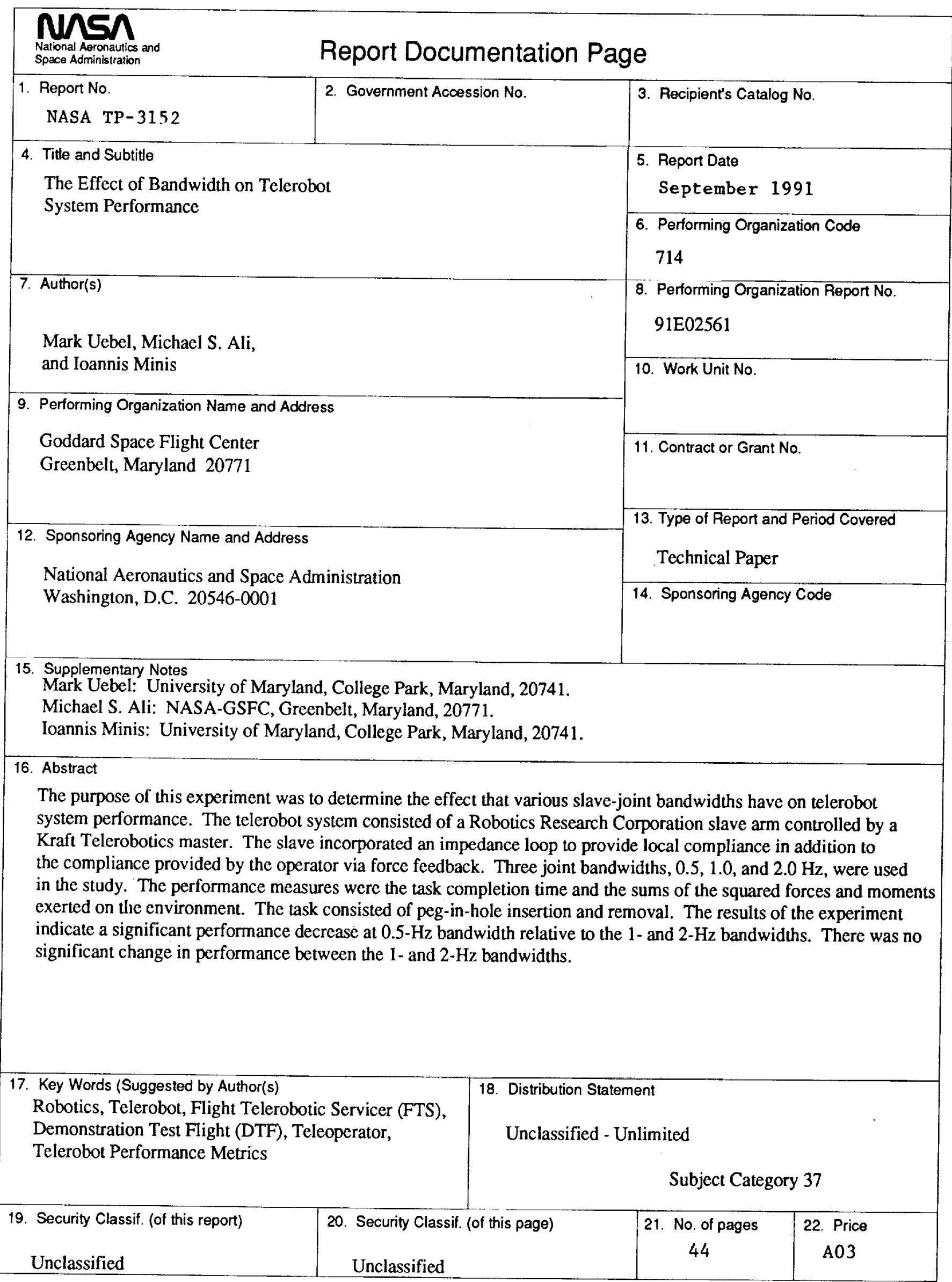


